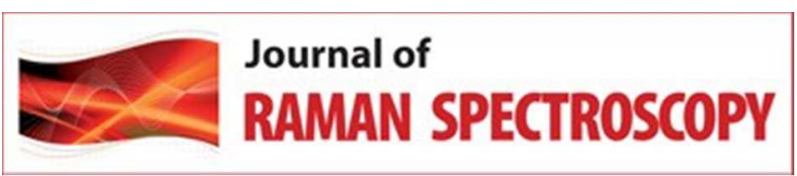

\title{
Amorphous Zinc Borate as a simple standard for baseline correction in Raman spectra
}

\begin{tabular}{|r|l|}
\hline Journal: & Journal of Raman Spectroscopy \\
\hline Manuscript ID & JRS-16-0266 \\
\hline Wiley - Manuscript type: & Research Article \\
\hline Date Submitted by the Author: & 02-Oct-2016 \\
\hline Complete List of Authors: & $\begin{array}{l}\text { Sanz, Aurelio; University of Valladolid, Unidad Asociada UVA-CSIC al } \\
\text { Centro de Astrobiología } \\
\text { Manrique, Jose; Centro de Astrobiologia, Unidad Asociada UVA-CSIC } \\
\text { Rull, Fernando; University, Fisica Materia Condesada } \\
\text { Medina-García, Jesus; Centro de Astrobiologia, Unidad Asociada UVA-CSIC }\end{array}$ \\
\hline Keywords: & $\begin{array}{l}\text { Raman spectroscopy, baseline correction, Zinc borate, etaloning, NIST } \\
\text { standard }\end{array}$ \\
\hline
\end{tabular}


Aurelio Sanz-Arranz ${ }^{1,2}$, Jose A. Manrique-Martinez ${ }^{1,2}$, Jesus Medina-Garcia ${ }^{1,2}$, Fernando RullPerez $^{1,2}$

\footnotetext{
${ }^{1}$ Associated Unit "ERICA": Advanced Spectroscopy applied to Earth and Planetary Sciences. Ave. Francisco Vallés, 8. Technology Park "Las Arroyadas". 47151 Boecillo, Valladolid, Spain. ERICA is Associated Unit of "University of Valladolid (UVa)", and "Center of Astrobiology (CAB)". CAB is a mix center from "Spanish National Research Council (CSIC)" and "National Institute of Aerospace Technology (INTA)".

${ }^{2}$ Department of Condensed Matter Physics, Crystallography and Mineralogy. University of Valladolid. Paseo de Belén, 7. 47011 Valladolid, Spain.
}

\begin{abstract}
.
In this paper we propose a simple solution to an usual problem that appears in the Raman analysis of some substances, which is the presence of weak Raman signals, probably in combination with a high intensity luminescence background; affected by the presence of distortions in the baseline. Under this conditions the spectroscopist has to face spectra hard to edit and correct, and thus, hard to study. There are already some standard solutions that allow the correction of spectra from relative intensity to absolute intensity, what solves this problem, and also allow quantitative analyses. But these solutions imply expensive standards or devices that could not be a worthy option if we don't need to work in absolute intensity or quantitative analysis of Raman spectra. The alternative DIY solution we propose in this paper is based on the use of amorphous zinc borate, an easy to find substance, which after an easy processing allows us to correct Raman spectra baseline qualitatively, offering a useful and economic reference when an absolute intensity correction is not needed. In order to evaluate the effectiveness of this procedure some spectra were corrected using amorphous zinc borate and then, compared the SNR of some Raman signals before and after this correction.
\end{abstract}

KEYWORDS: Raman spectroscopy, Raman standard, baseline correction, absolute intensity, NIST standard reference materials, calibrated tungsten halogen lamp, zinc borate.

\title{
INTRODUCTION.
}

Raman spectroscopy is a booming technique for its analytic capabilities under very concrete and complicated situations, as well as for its versatility. It's non-destructive and doesn't need direct contact with the sample ${ }^{1}$, performing analyses at a wide range of distances, from millimeters in the case of micro-Raman, to several meters for standoff Raman ${ }^{2}$. It is also a technique that is portable allowing in situ analyses thanks to portable Raman devices; therefore, it is not further restricted to a laboratory ${ }^{3}$. Furthermore, and thanks to the automatization, databases available and a widespread of its use in industry, Raman is no longer a technique restricted to specialized spectroscopists and scientists; and non-qualified personnel can perform sample analyses with the latest Raman spectrometers ${ }^{4}$, given that even the interpretation of spectra is now automatized thanks to the complete built in databases available with these Raman devices ${ }^{5}$.

Thanks to all these advantages, Raman spectroscopy has spread over a great variety of fields such as pharmaceutics, archeology, heritage, mineralogy, gemology, forensic science, polymers, etc ${ }^{6}$. It is also present in planetary exploration with a $532 \mathrm{~nm}$ Raman Laser Spectrometer in ESA's mission Exomars (RLS) ${ }^{7}$; and two spectrometers, a 
UV contact Raman Spectrometer (SHERLOQ) and a stand-off multitechnique instrument including also LIBS and fluorescence spectroscopy (SUPERCAM) ${ }^{8}$.

\section{Figure 1: General schematics of a Raman instrument.}

Most of nowadays Raman devices use a Raman probe-head as collection/focalization optics. This Raman head is connected to a spectrometer by a fiber glass, where the light is separated into its component wavelengths and focalized on a CCD detector, transforming the optical signal into digital information that can be handled by a computer with specific software for spectra study ${ }^{1}$. But, any optical device or detector introduces its signature during a spectrum acquisition process (this signature is called apparatus function) and since there is no perfect optical device or detector, the final baseline of the instrument is not perfect as well. This particular baseline is different for every instrument, and for some changes in the experimental setup ${ }^{9}$. Of course, the shape of this baseline affects the way an instrument receives the Raman signals ${ }^{10,11}$.

Figure 2 shows an example of a good and a bad Raman scatterers. The good scatterer gives a spectrum with an easy, even unnecessary, baseline correction. But the bad scatterer make things much harder for baseline correction, that is essential to obtain a representative result of the analyzed sample.

Figure 2: Raman spectra taken with the $785 \mathrm{~nm}$ device described in this article. (1) Limestone (polished solid). (2) Carbon tetrachloride (liquid). Both spectra uncorrected.

There are several approaches to solve this problem ${ }^{12,13,14}$. The method of interest for this paper is the absolute intensity correction of the instrument ${ }^{15,16}$. For this correction is necessary the use a calibrated light source for which we know perfectly the spectral distribution of the intensity ${ }^{15,17}$. Knowing the emission function of the source, and evaluating the detected spectra by our instrument we can obtain the apparatus function, where distortions as the etaloning ${ }^{1}$ are included and can be identified and removed. There are two main options to use as standard for this correction:

- A calibrated tungsten halogen lamp, which is a lamp certified to emit light with a very specific emission curve ${ }^{1}$.

- A luminescent intensity standard, which is a material that presents a very intense luminescence response to the excitation laser ${ }^{1}$. This material can be solid, like a rare-earth doped optical glass, or a solution of a fluorescent molecule ${ }^{15}$. The best examples of this option are the NIST Standard Reference Materials (SRM) belonging to $224 \mathrm{X}$ series $^{10,11}$.

Advantages and disadvantages of both correction methods are deeply discussed in the references provided ${ }^{1,10,11,15}$. The fact that in most of the cases it's not necessary an absolute intensity correction, only a baseline correction, led us to search for a simpler option. But there's a lack of bibliographic references about the question ${ }^{18}$.

We started looking for materials with a similar approach to the problem to the NIST standards. An ideal luminescent standard for Raman intensity calibration, as aforementioned NIST standards, would have several characteristics: a broad and featureless output over the relevant wavelength range; exactly reproduce the Raman sampling geometry; simple and easy to implement; require no additional instrument 
other than what is required to take the Raman spectrum; reproducible luminescence output; no sample heterogeneity; long-term stability with and without laser illumination ${ }^{1}$.

Based on our group's experience in the field and the great variety of samples we have analyzed in almost 30 years of existence ${ }^{19}$ to 25 , we started this search by the materials with a similar composition to NIST standards, and more specifically to SRM 2241 (intended for $785 \mathrm{~nm}$ excitation) and SRM 2242 (intended for $532 \mathrm{~nm}$ excitation). These standards are, respectively, a chromium doped (mole fraction of $0.202 \% \mathrm{Cr}_{2} \mathrm{O}_{3}$ ) sodium borosilicate matrix glass ${ }^{26}$, and a manganese-doped $\left(0.15\right.$ wt $\left.\% \mathrm{MnO}_{2}\right)$ borate matrix glass ${ }^{27}$. So we started evaluating different borates and borosilicates, and finally selected the zinc borate, a white substance, that presented a high luminescence, thermally processed to induce a transition to an amorphous phase ${ }^{28}$.

Zinc borate, $\mathrm{Zn}\left[\mathrm{B}_{3} \mathrm{O}_{4}(\mathrm{OH})_{3}\right]$, is an inorganic chemical compound with a wide presence in industrial processes ${ }^{29}$. Thanks to its low cost, zinc borate is used as an additive for polymers, ceramics, composites or coatings, among other uses. Zinc borate suffers some phase changes as temperature rises. At 290 으 begins it dehydration, being completely dehydrated at 420 o $\mathrm{C}$. This process produces an amorphous phase, with composition $2 \mathrm{ZnO} \cdot 3 \mathrm{~B}_{2} \mathrm{O}_{3}$, which is the interesting phase for the scope of this paper. This phase starts crystallizing at $6400^{\circ} \mathrm{C}$ in two different crystalline phases that melts at $870^{\circ} \mathrm{C}$ and $960^{\circ} \mathrm{C}$, respectively ${ }^{28}$.

Several tests were performed to characterize samples of zinc borate (ZB). Analyses included DSC, X-ray diffraction and Raman spectroscopy. The DSC shows two endothermic transitions and one exothermic. First endothermic starts at $201 \stackrel{\circ}{\circ}$, with a maximum at 368 으, the second endothermic takes place from 536 으 with its maximum at $425^{\circ} \mathrm{C}$ while the exothermic transition takes place between 630 and 698

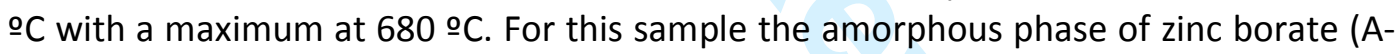

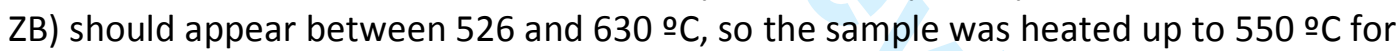
two hours to transform our ZB sample into A-ZB. Once cooled the A-ZB sample was analysed using $X$-Ray diffraction and Raman spectroscopy, and presenting no peaks for both spectra, confirming the amorphicity of the sample ${ }^{30}$.

Figure 3a: DSC analysis of a $\mathrm{Zn}_{3} \mathrm{~B}_{6} \mathrm{O}_{12} \cdot 3,5 \mathrm{H}_{2} \mathrm{O}$ sample.

Figure 3b: XRD analysis of a $\mathrm{Zn}_{3} \mathrm{~B}_{6} \mathrm{O}_{12} \cdot 3,5 \mathrm{H}_{2} \mathrm{O}$ sample unaltered (1) and heated up to 550 ㅇ for two hours (2).

Figure 3c: Raman analysis of a $\mathrm{Zn}_{3} \mathrm{~B}_{6} \mathrm{O}_{12} \cdot 3,5 \mathrm{H}_{2} \mathrm{O}$ sample unaltered (1) and heated up to $550 \stackrel{\circ}{C}$ for two hours (2). Both spectra uncorrected.

\section{EXPERIMENTAL SETUP.}

The Differential Scanning Calorimetry (DSC) analysis was made with a Mettler Toledo DSC30 calorimeter and a Mettler TC11 processor, in a temperature range between 25 and $700 \stackrel{\circ}{\circ}$. This analysis was performed by the department of Condensed Matter Physics, from University of Valladolid. 
The X-Ray Diffraction (XRD) analysis was made with a Philips PW1710 diffractometer, equipped with an automatic divergent slit graphite monochromator, and a copper anode. This analysis was performed by the Laboratory of Instrumental Techniques (LTI), from University of Valladolid.

The Raman $532 \mathrm{~nm}$ device was composed by: Elforlight G4 PSU laser. HoribaJobin Ybon Superhead Raman probe. Zeiss Axiotech 30 microscope, focusing with a Zeiss 50x long WD objective. Spectrometer and CCD from the Horiba-Jobin Ybon Induram industrial Raman system.

The Raman $633 \mathrm{~nm}$ device was composed by: Research Electro-Optics LSRP3501 laser (Helium-Neon, 632,8 nm). Kaiser OSI HFPH Raman probe. Nikon Eclipse E600 microscope, focusing with a Nikon 100x long WD objective. Kaiser OSI Holospec 1.8i spectrometer. Andor DV420A-OE-130 CCD.

The Raman $785 \mathrm{~nm}$ device was composed by: BWTEK BRM-OEM-785 laser. BWTEK BAC100-785E Raman probe, focusing with a approx 20x lens. BWTEK Prime T BTC661E-785CUST spectrometer. Hamamatsu S10141-1107S CCD.

The FT-Raman $1064 \mathrm{~nm}$ device was a Bruker RFS100/S spectrometer, with no Raman head probe. The 785, 633 and $532 \mathrm{~nm}$ Raman spectrometers described before were all coupled to their Raman heads using optic fibers.

The calibrated tungsten-halogen lamp used as intensity reference was the Kaiser OSI HCA-0244a Raman Calibration Accessory. Spectral intensity calibration range: $500-1100 \mathrm{~nm}^{31}$. That range covers the three visible laser Raman devices, but not the FT-Raman.

Two units of NIST SRM were used as well, one unit of the SRM 2241 (for $785 \mathrm{~nm}$ Raman devices) and one unit of the SRM 2242 (for $532 \mathrm{~nm}$ Raman devices). They were used to compare with the A-ZB and the KOSI HCA calibrated lamp, correcting the baseline of some Raman spectra recorded for this test.

To verify how good is the A-ZB as reference for qualitative baseline correction, our group used all the excitation wavelengths available in our laboratory. These instruments are very heterogeneous, using different optical designs and detectors, and this fact provides a good versatility to this test. We also used different focalization/collection optics, so we could have also different spot sizes over the sample. A range of laser powers from a few $\mathrm{mW}$ to hundreds of $\mathrm{mW}$ lead to a wide range of irradiances. As a result we could try A-ZB in a great variety of different conditions representative of usual situations for any Raman analyst.

Figure 4: Comparison of the luminescence spectrum of $A-Z B$ as obtained with different instruments: (1) $532 \mathrm{~nm}$, (2) $633 \mathrm{~nm}$, (3) $785 \mathrm{~nm}$, (4) $1064 \mathrm{~nm}$. Spectra intensity normalized to unit.

\section{CORRECTION PROCEDURE.}


After the processing described before the A-ZB powder suffered no further alterations but its compression into several pills using a hydraulic press and 10 tons of pressure. The pills obtained were fragile (and broke); however, small fragments presenting a surface of several square millimeters could be obtained. That fragments can be handled and analyzed just like another sample. It's easy to obtain a good spectrum of A-ZB luminiscence, with a high intensity, using the whole dynamic range of the detector but avoiding its saturation in the entire range of the CCD.

Having this into account, we obtained several spectra of the A-ZB luminescence, averaging a great number of accumulations to avoid shot noise ${ }^{1}$ in the baseline. The noise has a high impact on the quality of the correction, since the noise introduced in a spectrum of A-ZB sums to the existing noise in the spectrum to correct after this procedure. No further digital processing, as Savitzky-Golay filter, is recommended for the A-ZB spectra since this could reduce the efficiency of this procedure in the elimination of some kind of noise (high frequency fixed-pattern noise) and spectral artifacts (filter transmission ripple) ${ }^{10,11}$.

Figure 5: comparison between the spectrum of the A-ZB luminescence (1), the KOSI HCA calibration lamp emission (2), and the NIST SRM 2242 or 2241 (3). Spectra intensity normalized to unit.

Figure 5a: $532 \mathrm{~nm}$ Raman spectrometer.

Figure 5b: $633 \mathrm{~nm}$ Raman spectrometer.

Figure 5c: $785 \mathrm{~nm}$ Raman spectrometer.

The correction procedure with the A-ZB spectra is similar to the one described in the standard correction using a NIST SRM ${ }^{10,11,26,27}$. It consists basically in dividing, point by point, the intensity of the problem spectrum by the intensity of the reference, in this case the spectrum of A-ZB.

\section{EXPERIMENTAL RESULTS.}

To evaluate the goodness of our method for baseline correction we used two different approaches. The first approach is fully qualitative and consists on the manual correction of selected samples, and the second approach (more quantitative) consists on an evaluation of the signal-to-noise ratio (SNR) of different Raman signals present on the spectra before and after the correction.

For these test we selected two different samples, based on our own experience. The first sample was a piece of limestone, polished solid (mineral composition $\mathrm{CaCO}_{3}$ and organic calcareous material), and a piece of polyethylene [PE, polymer composition $\left(\mathrm{CH}_{2}-\mathrm{CH}_{2}\right)_{\mathrm{n}}$ ] heavily charged with $50 \%$ of talc [mineral composition $\mathrm{Mg}_{3} \mathrm{Si}_{4} \mathrm{O}_{10}(\mathrm{OH})_{2}$ ]. Both samples present high levels of luminescence that make difficult, but not impossible, their analysis with Raman spectroscopy using visible wavelengths; and also show the baseline defects on the instruments used for their analysis.

A total of 9 consecutive spectra of limestone and PE+talc were acquired with all the Raman instruments described, under the same conditions for SNR evaluation. Those were fast, low quality spectrum. An additional high quality spectrum of each sample 
was acquired, using more scans and a higher acquisition time. Also, high quality spectrum of A-ZB, KOSI HCA lamp, and NIST standards were acquired with the respective devices. The relative intensity of that reference spectra was normalized to unit in every case.

\section{- 532 nm Raman Spectrometer}

The baseline of this $532 \mathrm{~nm}$ Raman device shows remarkable ripples, attributable to the optical response of the Horiba-JY Superhead probe. In the figure 6 is shown a comparison between the low noise spectrum of the limestone, and the spectrum corrected using A-ZB, the calibration lamp, and the NIST SRM. The ripples in the original spectrum disappear after the correction with $A-Z B$, showing a weak and wide signal centered around $1086 \mathrm{~cm}^{-1}$, corresponding to the most intense Raman band of the limestone. In the case of the spectrum corrected using the KOSI HCA lamp some residual distortions in the baseline still remain, masking the Raman band mentioned before. Neither the NIST SRM obtains a good baseline correction.

Figure 6a: $532 \mathrm{~nm}$ Raman limestone spectra, (1) original, (2) A-ZB corrected, (3) KOSI HCA lamp corrected, (4) NIST SRM 2242 corrected.

Figure 6b: detail of limestone's main band region around $1086 \mathrm{~cm}^{-1}$.

In the figure 7 is shown the same comparison for the PE+talc sample. In addition to the curls there appear two intense broad signals that were assumed to be the luminescence response of the sample, and so, those signals cannot be corrected using this method. Despite of this, in the original spectrum only the most intense Raman signal of the PE was visible (around $2880 \mathrm{~cm}^{-1}$ ). All the other signals are masked by the distortions introduced by the Raman head, making impossible to distinguish between those distortions or the signals from the sample. However, after the correction with this method, those signals appear clearly between 360 and $1440 \mathrm{~cm}^{-1}$. This situation is similar compared to the spectrum corrected using the lamp and the NIST SRM.

Figure 7a: $532 \mathrm{~nm}$ Raman spectrum of PE+talc, (1) original, (2) A-ZB corrected, (3) KOSI HCA lamp corrected, (4) NIST SRM 2242 corrected.

Figure 7b: detail of the low Raman shift region.

Calculations to obtain the SNR were made using 9 consecutive spectra from each sample, not shown in figures. We chose 9 spectra based on the estimation that this should be a population enough to obtain an acceptable value for the Relative Standard Deviation (RSD), 10\% maximum; this estimation shown to be correct excepting for the weakest signals. The SNR for a particular measurement is rigorously defined as the inverse of the relative standard deviation of the measured value. The SNR for the peak intensity of a Raman band is the average peak intensity $(\bar{I})$, usually above the baseline, divided by the standard deviation of the peak intensity $\left(\bar{\sigma}_{1}\right)^{1}$.

$$
S N R=\frac{\bar{I}_{i}}{\bar{\sigma}_{I}}=\frac{\bar{I}_{i}}{\sqrt{\frac{\sum\left(I_{i}-\bar{I}_{i}\right)^{2}}{n}}}
$$


Where $i$ goes from 1 to the total number of spectra used for the evaluation $(n)$.

Looking back at the SNR variation on the $532 \mathrm{~nm}$ spectra, three Raman signals from the PE+talc sample were chosen. No SNR belonging to a limestone signal was evaluated on the registered spectra, because there were no clear Raman signals inside the noise.

Figure 8: Raman spectra using $532 \mathrm{~nm}$ of a limestone sample, (1) 1 scan, (2) 50 scan, keeping all the other acquisition parameters the same.

The quantitative evaluation on the SNR variation belonging to the three chosen signals is presented on table 1 . Only the most intense signal at $2881 \mathrm{~cm}^{-1}$ allows to obtain a significative result, with an RSD of approximately $10 \%$. The correction with A-ZB decreases the intensity (almost half of it) and the SNR from the signal, although the SNR stays on the same order. The other two signals produce a superior RSD, and a SNR of approximately 3 , due to its weak intensity. Through this method the quality of the correction can be appreciated, since it allows distinguishing signals that are not seen at glance on the original spectrum.

\section{TABLE 1}

\section{- 633 nm Raman Spectrometer}

The Kaiser OSI Holospec 1.8i spectrometer has a two track fixed diffraction rating, first track covers from 0 to $2000 \mathrm{~cm}^{-1}$ and the second from 2000 to $3800 \mathrm{~cm}^{-1}$. That is the cause of the vertical discontinuity present at $2000 \mathrm{~cm}^{-1}$. On the spectrum corrected with the $\mathrm{A}-\mathrm{ZB}$, the curvy luminiscence is cleared obtaining a spectrum with an almost straight base line. That effect is not achieved on the spectrum corrected with the Kaiser OSI HCA lamp, which turns the two big initial curves in one.

Figure 9a: $633 \mathrm{~nm}$ Raman spectra of a limestone sample (1) original, (2) A-ZB corrected, (3) KOSI HCA lamp corrected.

Figura 9b: Detail of the Raman signals range from the previous figure.

On figure 10 we show the spectra of the PE+Talc taken with the Raman $633 \mathrm{~nm}$ instrument. The luminescence coming from the sample is so intense, that it practically covers the Raman signals of most of the spectrum. The only evident Raman signals are the ones over $2900 \mathrm{~cm}^{-1}$; for that reason the spectra wouldn't be entirely useful in a real analysis. It's an example that the proposed correction can't correct everything.

Figure 10a: $633 \mathrm{~nm}$ Raman spectra of PE+talc, (1) original, (2) A-ZB corrected, (3) KOSI HCA lamp corrected.

Figure 10b: Detailed view of the Raman signals around $2900 \mathrm{~cm}^{-1}$.

For that reason, the SNR variation was calculated for two limestone signals and one $P E+$ talc. Table 2 gathers the results. In general, it could be said that the SNR does not suffer any variations after being corrected.

TABLE 2 


\section{- 785 nm Raman Spectrometer}

Most of the spectra obtained with our Raman device, a BWTEK Prime T spectrometer with a Hamamatsu CCD, shows a succession of undulations (etaloning), that comprises almost all the useful range from the instrument, from 200 to $2400 \mathrm{~cm}^{-1}$. As seen on figure 2, the etaloning considerably disrupts the baseline in spectra coming from samples that provide weak Raman signals, of similar intensity to this effect.

On figure 11 we compare both correction methods for the limestone spectra. On the original spectrum only the $1086 \mathrm{~cm}^{-1}$ signal emerges clearly over the etaloning, the 280 $\mathrm{cm}^{-1}$ signal is intuited over the crest of a bigger undulation and the others are masked. In the corrected spectrum with the A-ZB the wavy baseline is almost corrected and the weaker signals, between 155 and $711 \mathrm{~cm}^{-1}$ emerge clearly. On the spectrum corrected with the KOSI HCA lamp all these signals are also visible, although the etaloning correction is not as good and a slight residue coming from the undulations can be observed. And the NIST SRM 2241 doesn't correct the etaloning of the baseline really.

Figure 11a: $785 \mathrm{~nm}$ spectra of a limestone sample, (1) original, (2) A-ZB corrected, (3) KOSI HCA lamp corrected, (4) NIST SRM 2241 corrected.

Figure 11b: Detail of the region of interest (without the SRM 2241 spectrum).

Figure 11c: Detail of spectrum (2), showing how well A-ZB corrects the etaloning artifacts.

Figure 12 shows the same comparison for the PE+Talc. On the original spectrum, almost all the Raman signals are influenced by etaloning. The wider signals (with maximums of 1061, 1294 and $1437 \mathrm{~cm}^{-1}$ ) get their band profiles altered, because they're over bigger undulations. In the spectrum corrected with A-ZB there's almost no residue of etaloning and the wider signals recover their usual profile. It is important to highlight the amplification suffered around the $2881 \mathrm{~cm}^{-1}$ region on the spectrum corrected with A-ZB; this is due to the low intensity of the A-ZB spectrum in that region. In the spectrum corrected with the lamp, the effect is practically the same. Again, the NIST SRM 2241 doesn't correct the etaloning.

Figure 12a: $785 \mathrm{~nm}$ Raman spectra of PE+talc, (1) original, (2) A-ZB corrected, (3) KOSI HCA lamp corrected, (4) NIST SRM 2241 corrected.

Figure 12b: Detail of the low Raman shift region (without the SRM 2241 spectrum).

Figur3 12c: Detail of the range around $2900 \mathrm{~cm}^{-1}$.

The SNR variation was calculated for two signals, one from PE+talc and one from limestone. Table 3 gathers the results. The $194 \mathrm{~cm}^{-1} \mathrm{PE}+$ talc signal decreases its intensity to a bit more than half of it and the SNR remains almost the same. The 1086 $\mathrm{cm}^{-1}$ limestone signal decreases its intensity on one third and the SNR also decreases but not as much. The $2881 \mathrm{~cm}^{-1} \mathrm{PE}+$ talc signal increases its intensity drastically, more than 14 times; nevertheless the SNR decreases on almost one third. The decrease is due to an increase, of almost 22 times, produced by the standard deviation of the signals intensity. 
TABLE 3

\section{- 1064 nm Raman Spectrometer}

The Bruker RFS100/S spectrometer is the biggest, more complex and most expensive of all the instruments that were used for the test. Its functioning is also different, and it shows various advantages and disadvantages ${ }^{1}$. Its baseline presents two noisy areas, from 400 to $700 \mathrm{~cm}^{-1}$, and 1950 to $2500 \mathrm{~cm}^{-1}$. After analyzing the samples, it was evident that the weaker the Raman signals are, the more disturbing these interferences tend to be. Specially in the range from 400 to $700 \mathrm{~cm}^{-1}$, which is a typical region of interest when analyzing most of the samples.

The figure 13 shows the comparison between the limestone original spectrum and the spectrum corrected with A-ZB. In the corrected spectrum, the interferences between 400 and $700 \mathrm{~cm}^{-1}$ disappear almost entirely and the curvy baseline is corrected. Wider weaker signals corresponding to amorphous carbon, centered on 1310 y $1590 \mathrm{~cm}^{-1}$, can be seen while before were masked by the curvy baseline (and were not detected by the other instruments involved on the test). The interferences between 1950 y 2500 $\mathrm{cm}^{-1}$ don't completely disappear, although they are acceptably attenuated. The amplification results noticeable from $3200 \mathrm{~cm}^{-1}$, since the intensity of the corrected spectrum is close to cero in that area.

Figure 13: FT-Raman spectra of a limestone, sample (1) original, (2) A-ZB corrected.

The figure 14 shows the usual comparison for the PE+talc. In this case the original spectrum had almost no artifacts or other defects to correct.

Figure 14a: FT-Raman spectra of PE+talc, (1) original, (2) A-ZB corrected.

Figure 14b: Detail of the low Raman shift region.

The SNR variation was calculated for two signals of PE+talc and one from limestone. Table 4 gathers the results. The PE+talc at $194 \mathrm{~cm}^{-1}$ signal decreases its intensity to a third; the limestone signal at $1086 \mathrm{~cm}^{-1}$ keeps a similar intensity and the PE+talc at $2881 \mathrm{~cm}^{-1}$ increases three times its intensity. The SNR on all the signals is maintained almost invariable after the correction.

\section{TABLE 4}

\section{- Comparison of the results among different instruments.}

The figure 15 shows the spectra corrected with the A-ZB from the different instruments used in this test. The purpose of this comparison is just to put together all the spectra and make easier to visualize the effects of the correction. For that purpose at this stage the baseline of the A-ZB divided spectra was made horizontal using straight segments, always as less number as possible. The intensity of all the spectra was also normalized to unit.

In general, the result after the correction is satisfactory in the visible instruments, keeping in mind how harsh were the initial baselines, and how the distortions affected most of the weak signals (figures 6 to 12). FT-Raman spectra can be considered as a 
reference, since the spectral quality is better, due to the good SNR that the weak signals present. FT-Raman is a superior instrument compared with the others, taking into account that it is a typical good choice for luminescent samples, and the optical performance of the system.

Among its limitations, instruments using visible laser excitation got very good results with the samples. The $532 \mathrm{~nm}$ instrument is badly affected by the luminescence of the limestone and the PE+talc in the low Raman shift emission. The $633 \mathrm{~nm}$ instrument is greatly affected by the emission produced by the PE+talc in low Raman shift and the spectrum in that range results not representative. The signal centered in $2900 \mathrm{~cm}^{-1}$ of the PE+talc is deformed by the $785 \mathrm{~nm}$ instrument, which could be attributed to the low sensibility of the CCD in that area (practically at the end of its useful range).

As conclusion, thanks to the correction done with the A-ZB, Raman spectra with useful information has been gathered starting with distorted or etaloned original spectra (532 and $785 \mathrm{~nm}$ instrument) that were not useful before.

Figure 15: Spectra A-ZB corrected. (1) 532 nm, (2) 633 nm, (3) 785 mn, (4) FT-Raman $1064 \mathrm{~nm}$.

Figure 15a: limestone spectra.

Figure 15b: PE+talc spectra (low Raman shift).

Figure 15c: PE+talc spectra (high Raman shift).

\section{CONCLUSIONS.}

We have demonstrated how the amorphous phase of zinc borate can be used as an affordable alternative to the more complex and demanding standard solutions when just a qualitative baseline correction is needed. We have used this solution with different excitation wavelengths and spectrometers, revealing weak Raman signals that were masked by instrumental artifacts or luminescence.

Our method using A-ZB could be an interesting option for the post-treatment of spectra and could also be used as a standard with an improvement of the presentation (to get a flat homogenous surface) and a deeper characterization of its luminescent emission. As Raman spectroscopy gets more usual in different fields of use, this versatile and easy to use standard could have high possibilities of application.

One of the fields where Raman is spreading is on planetary sciences and robotic exploration. Our group participates in two instruments on board of two missions that will bring Raman spectroscopy to Mars: RLS instrument in Exomars, and Supercam on board Mars 2020. Given the physical stability of the A-ZB, this sample could be an easy to qualify material and an interesting calibration sample for intensity purposes. Also, with SuperCam specially in mind; this sample with a well characterized luminescence signal in terms of time response could be of interest in Time-Resolved systems. 


\section{ACKNOWLEDGEMENTS.}

The authors would like to thank the University of Valladolid and the Astrobiology Center in Madrid for their unconditional support. Special thanks to Carolina Ochoa for her help in the redaction this paper. 


\section{REFERENCES.}

1: Richard L. McCreery. Raman spectroscopy for chemical analysis (Chemical analysis; v. 157). 1st edition, 2000. Wiley-Interscience; a John Wiley \& Sons, Inc, Publication. ISBN 0-471-25287-5.

2: Analysis of Arctic ices by Remote Raman Spectroscopy. F. Rull, A. Vegas, A. Sansano, P. Sobrón. Spectrochimica Acta Part A Molecular and Biomolecular Spectroscopy, May2011, 80(1), 148-155.

3: Spectrometers: miniature spectrometer designs open new applications potential. Robert V. Chimenti and Robert J. Thomas. Whitepaper of Laser Focus World. 05/01/2013.

http://www.laserfocusworld.com/articles/print/volume-49/issue05/features/spectrometers--miniature-spectrometer-designs-open-new-applicati.html

4: Comparison of Laboratory and Handheld Raman Instruments for the Identification of Counterfeit Medicines. Robert Watt, Tony Moffat, Sulaf Assi. Whitepaper of Spectroscopy Online Special Issues. Jun 01, 2011.

http://www.spectroscopyonline.com/comparison-laboratory-and-handheld-ramaninstruments-identification-counterfeit-medicines

5: Pros and cons of using correlation versus multivariate algorithms for material identification via handheld spectroscopy. Katherine A. Bakeev and Robert V. Chimenti. Whitepaper of European Pharmaceutical Review. 15 July 2013.

http://www.europeanpharmaceuticalreview.com/19813/whitepapers/materialidentification-using-handheld-spectroscopy

6: Raman Spectroscopy Applied to Earth Sciences and Cultural Heritage. Edited by J. Dubessy, M.-C. Caumon, and F. Rull. European Mineralogical Union Notes in Mineralogy (Vol. 12). 1st edition, 2012. ISBN 978-0-903056-31-1.

7: G Lopez-Reyes, F. Rull, G. Venegas, F. Westall, F. Foucher, N. Bost, A. Sanz, A. CatalaEspi, A. Vegas, I. Hermosilla, A. Sansano, J. Medina. Analysis of the scientific capabilities of the ExoMars Raman Laser Spectrometer instrument. European Journal of Mineralogy, 25, 721-733. 2013. 
8: http://mars.nasa.gov/mars2020/mission/instruments

9: Two accurate methods to obtain the spectral sensitivity of a Raman spectrometer device. R. Ouillon and S. Adam. Journal of Raman Spectroscopy. Volume 12, Issue 3, pages 281-286, June 1982.

10: Relative Intensity Correction of Raman Spectrometers: NIST SRMs 2241 Through 2243 for $785 \mathrm{~nm}, 532 \mathrm{~nm}$, and $488 \mathrm{~nm} / 514.5 \mathrm{~nm}$ Excitation. S.J. Choquette, E.S. Etz, W.S. Hurst, D.H. Blackburn, and S.D. Leigh. Applied Spectroscopy, Vol. 61, Issue 2, 117129 (2007).

11: ASTM standard E2911 - 13. Standard Guide for Relative Intensity Correction of Raman Spectrometers. Published July 2013.

12: Automated method for subtraction of fluorescence from biological Raman spectra. C.A. Lieber, A. Mahadevan-Jansen. Applied Spectroscopy, Nov-2003, 57(11), 13631367.

13: A Model-Free, Fully Automated Baseline-Removal Method for Raman Spectra. H.G. Schulze, R.B. Foist, K. Okuda, A. Ivanov, R.F.B. Turner. Applied Spectroscospy, January 2011, vol. 65 no. $1,75-84$.

14: Baseline removal in Raman spectroscopy: optimization techniques. C. Carey, M.D. Dyar, T.F. Boucher, S. Giguere, C.M. Hoff, L.B. Breitenfeld, M. Parente, T.J. Tague, P. Wang, and S.Mahadevan. Conference Paper in 46th Lunar and Planetary Science Conference, LPSC 2015. The Woodlands, Texas (U.S.A.), March 16-20, 2015.

15: Richard L. McCreery. Photometric Standards for Raman Spectroscopy. Reproduced from: Handbook of Vibrational Spectroscopy. John Wiley \& Sons Ltd, Chichester, 2002.

16: Standardization of Raman spectra for transfer of spectral libraries across different instruments. J.D. Rodriguez, B.J. Westenberger, L.F. Buhsea, J.F. Kauffman. Analyst (2011), 136, 4232-4240. 
17: Application of quantitative Raman spectroscopy for the monitoring of polymorphic transformation in crystallization processes using a good calibration practice procedure. E. Simone, A.N. Saleemi, Z.K. Nagy. Chemical Engineering Research and Design. April 2014, Volume 92, Issue 4, Pages 594-611.

18: Calibration between fiber-optic probe based Raman spectroscopy systems. Brittany Caldwell. Thesis for the degree of Master in Biomedical Engineering. Graduate School of Vanderbilt University. December, 2011.

19: Polarized Raman spectra of aqueous solutions and band component analysis. F. Rull, C. Prieto, F. Sobrón. Journal of Molecular Structure, Mar-1986, 143, 305-308.

20: Estimation of Crystallinity in Polyethylene by Raman Spectroscopy. F. Rull, A.C. Prieto, J.M. Casado, F. Sobrón, H.G.M. Edwards. Journal of Raman Spectroscopy, Aug1993, 24(8), 545-550.

21: FT-Raman spectroscopic characterization of pigments in the mediaeval frescoes at Convento de la Peregrina, Sahagún, Léon, Spain. F. Rull, H.G.M. Edwards, A. Rivas, L. Drummond. Journal of Raman Spectroscopy, Apr-1999, 30(4), 301-305.

22: Comparative micro-Raman study of the Nakhla and Vaca Muerta meteorites. F. Rull, J. Martinez-Frías, A. Sansano, J. Medina, H.G.M. Edwards. Journal of Raman Spectroscopy, Jun-2004, 35(6), 497-503.

23: A Raman spectral study of stream waters and efflorescent salts in Rio Tinto, Spain. P. Sobrón, A. Sanz, T. Acosta, F. Rull. Spectrochimica Acta Part A. 71, (2009), 16781682.

24: Evaluation of salmon adhesion on PET-metal interface by ATR, FT-IR, and Raman spectroscopy. E. Zumelzu, M. J. Wehrhahn, F. Rull, H. Pesenti, O. Muñoz, R. Ugarte. Journal of Spectroscopy, volume 2015, article ID 835798, 7 pages.

25: Effect of different broad waveband lights on membrane lipids of a Cyanobacterium, Synechococcus sp., as determined by UPLC-QToF-MS and vibrational spectroscopy. $O$. Montero, M. Velasco, A. Sanz-Arranz, F. Rull. Biology - Open Access Biological Sciences Journal, 5(2), 22 (2016).

26: Steven J. Choquette and Robert L. Watters, Jr. National Institute of Standards \& Technology (NIST) Certificate Standard Reference Material ${ }^{\circledR}$ (SRM) 2241. Relative Intensity Correction Standard for Raman Spectroscopy: 785 nm Excitation. Certificate Issue Date: 24 August 2015.

https://www-s.nist.gov/srmors/view_cert.cfm?srm=2241 
27: Anne L. Plant and Robert L. Watters, Jr. National Institute of Standards \& Technology (NIST) Certificate Standard Reference Material ${ }^{\circledR}$ (SRM) 2242. Relative Intensity Correction Standard for Raman Spectroscopy: 532 nm Excitation. Certificate Issue Date: 22 October 2013.

https://www-s.nist.gov/srmors/view_cert.cfm?srm=2242

28: David M. Schubert, Fazlul Alam, Mandana Z. Visi, and Carolyn B. Knobler. Structural Characterization and Chemistry of the Industrially Important Zinc Borate, Zn[B3O4(OH)3]. Chem. Mater., Vol. 15, No. 4, 866-871, 2003.

29: Zinc Borate tech data sheet. The Chemical Company.

https://www.thechemco.com/wp-content/uploads/2012/03/Zinc-Borate-TDS-TCC.pdf

30: Amorphous zinc borate as a low-cost standard for baseline correction in Raman spectra. A. Sanz-Arranz, J.A. Manrique-Martinez, J. Medina-Garcia, F. Rull-Perez. Poster. XII International Conference GeoRaman 2016. Novosibirsk (Russia), 9/15-JUN2016.

31: http://www.kosi.com/Raman_Spectroscopy/ra-calibrationaccessory.php?ss=500 


\section{TABLE LIST}

- TABLE 1:

\begin{tabular}{|l|l|l|l|l|l|l|l|}
\hline $\begin{array}{l}\text { Raman } \\
532 \mathrm{~nm}\end{array}$ & \multicolumn{3}{|l|}{ PE+talc 194 $\mathrm{cm}^{-1}$} & \multicolumn{2}{l|}{ PE+talc $1063 \mathrm{~cm}^{-1}$} & \multicolumn{2}{l|}{ PE+talc $2881 \mathrm{~cm}^{-1}$} \\
\hline Spectra & Original & $\begin{array}{l}\text { Corrected } \\
\text { with A-ZB }\end{array}$ & Original & $\begin{array}{l}\text { Corrected } \\
\text { with A-ZB }\end{array}$ & Original & $\begin{array}{l}\text { Corrected } \\
\text { with A-ZB }\end{array}$ \\
\hline $\bar{I}$ (a.u.) & 58 & 64 & 75 & 67 & 1243 & 714 \\
\hline $\bar{\sigma}$ (a.u.) & 15.5 & 21.3 & 32.9 & 20.8 & 107.9 & 78.0 \\
\hline $\begin{array}{l}\text { RSD (\% } \\
\bar{I})\end{array}$ & $26.8 \%$ & $33.4 \%$ & $43.6 \%$ & $30.9 \%$ & $8.7 \%$ & $10.9 \%$ \\
\hline SNR & 3.7 & 3.0 & 2.3 & 3.2 & 11.5 & 9.1 \\
\hline
\end{tabular}

Table 1, Raman $532 \mathrm{~nm}$ : average peak intensity $(\bar{I})$, standard deviation of the peak intensity $(\bar{\sigma})$, relative standard deviation $\operatorname{RSD}(\% \bar{I})$, and signal-noise ratio (SNR) calculated from three Raman bands of PE+talc (9-population-spectrum), original and corrected with A-ZB.

- TABLE 2

\begin{tabular}{|l|l|l|l|l|l|l|l|l|}
\hline $\begin{array}{l}\text { Raman } \\
633 \mathrm{~nm}\end{array}$ & \multicolumn{2}{|l|}{ limestone $280 \mathrm{~cm}^{-1}$} & \multicolumn{2}{|l|}{ limestone $1086 \mathrm{~cm}^{-1}$} & \multicolumn{2}{l|}{ PE+talc $2881 \mathrm{~cm}^{-1}$} \\
\hline Spectra & Original & $\begin{array}{l}\text { Corrected } \\
\text { with A-ZB }\end{array}$ & Original & $\begin{array}{l}\text { Corrected } \\
\text { with A-ZB }\end{array}$ & Original & $\begin{array}{l}\text { Corrected } \\
\text { with A-ZB }\end{array}$ \\
\hline $\bar{I}$ (a.u.) & 131 & 206 & 578 & 530 & 828 & 548 \\
\hline $\bar{\sigma}$ (a.u.) & 20.3 & 26.3 & 26.1 & 24.3 & 33.3 & 19.7 \\
\hline $\begin{array}{l}\text { RSD (\% } \\
\bar{I})\end{array}$ & 15.5 & 12.8 & 4.5 & 4.6 & 4.0 & 3.6 \\
\hline SNR & 6.4 & 7.8 & 22.2 & 21.8 & 24.9 & 27.9 \\
\hline
\end{tabular}


Table 2, Raman $633 \mathrm{~nm}$ : average peak intensity $(\bar{I})$, standard deviation of the peak intensity $(\bar{\sigma})$, relative standard deviation $\operatorname{RSD}(\% \bar{I})$, and signal-noise ratio (SNR) calculated from two Raman bands of limestone and one of PE+talc (9-populationspectrum), original and corrected with A-ZB.

- TABLE 3:

\begin{tabular}{|l|l|l|l|l|l|l|l|}
\hline $\begin{array}{l}\text { Raman } \\
785 \mathrm{~nm}\end{array}$ & \multicolumn{3}{|l|}{ PE+talc $194 \mathrm{~cm}^{-1}$} & \multicolumn{3}{|l|}{ limestone $1086 \mathrm{~cm}^{-1}$} & \multicolumn{2}{l|}{ PE+talc $2881 \mathrm{~cm}^{-1}$} \\
\hline Spectra & Original & $\begin{array}{l}\text { Corrected } \\
\text { with A-ZB }\end{array}$ & Original & $\begin{array}{l}\text { Corrected } \\
\text { with A-ZB }\end{array}$ & Original & $\begin{array}{l}\text { Corrected } \\
\text { with A-ZB }\end{array}$ \\
\hline $\bar{I}$ (a.u.) & 1369 & 792 & 1476 & 932 & 886 & 12565 \\
\hline $\bar{\sigma}$ (a.u.) & 151.1 & 86.0 & 123.8 & 97.9 & 36.8 & 800.3 \\
\hline $\begin{array}{l}\text { RSD (\% } \\
\bar{I})\end{array}$ & 11.0 & 10.9 & 8.4 & 10.5 & 4.2 & 6.4 \\
\hline SNR & 9.1 & 9.2 & 11.9 & 9.5 & 24.1 & 15.7 \\
\hline
\end{tabular}

Table 3, Raman $785 \mathrm{~nm}$ : average peak intensity $(\bar{I})$, standard deviation of the peak intensity $(\bar{\sigma})$, relative standard deviation $\operatorname{RSD}(\% \bar{I})$, and signal-noise ratio (SNR) calculated from two Raman bands of PE+talc and one of limestone (9-populationspectrum), original and corrected with A-ZB.

- TABLE 4:

\begin{tabular}{|l|l|l|l|l|l|l|l|}
\hline $\begin{array}{l}\text { FT-Raman } \\
1064 \mathrm{~nm}\end{array}$ & \multicolumn{2}{|l|}{ PE+talc $194 \mathrm{~cm}^{-1}$} & \multicolumn{2}{|l|}{ limestone $1086 \mathrm{~cm}^{-1}$} & \multicolumn{2}{l|}{ PE+talc $2881 \mathrm{~cm}^{-1}$} \\
\hline Spectra & Original & $\begin{array}{l}\text { Corrected } \\
\text { with A-ZB }\end{array}$ & Original & $\begin{array}{l}\text { Corrected } \\
\text { with A-ZB }\end{array}$ & Original & $\begin{array}{l}\text { Corrected } \\
\text { with A-ZB }\end{array}$ \\
\hline $\bar{I}$ (a.u.) & 0.0205 & 0.0063 & 0.113 & 0.094 & 0.119 & 0.368 \\
\hline $\bar{\sigma}$ (a.u.) & 0.0015 & 0.0005 & 0.0126 & 0.0105 & 0.0066 & 0.0211 \\
\hline
\end{tabular}




\begin{tabular}{|l|l|l|l|l|l|l|l|}
\hline RSD $(\% \bar{I})$ & 7.6 & 7.9 & 11.2 & 11.2 & 5.6 & 5.7 \\
\hline SNR & 13.2 & 12.6 & 9.0 & 8.9 & 18.0 & 17.4 \\
\hline
\end{tabular}

Table 4, FT-Raman $1064 \mathrm{~nm}$ : average peak intensity $(\bar{I})$, standard deviation of the peak intensity $(\bar{\sigma})$, relative standard deviation RSD $(\% \bar{I})$, and signal-noise ratio (SNR) calculated from two Raman bands of $\mathrm{PE}+$ talc and one of limestone (9-populationspectrum), original and corrected with A-ZB. 


\section{SPECTROMETER}

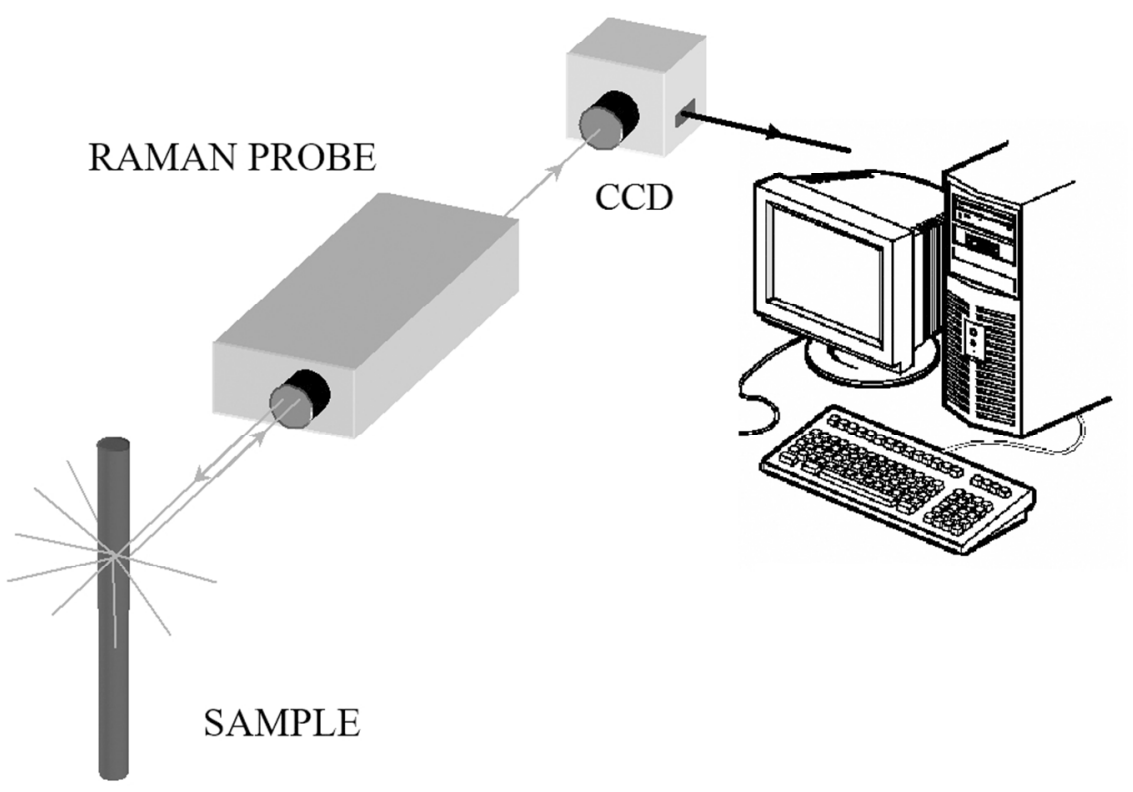

Raman spectrometer general schematics $412 \times 289 \mathrm{~mm}(72 \times 72 \mathrm{DPI})$ 


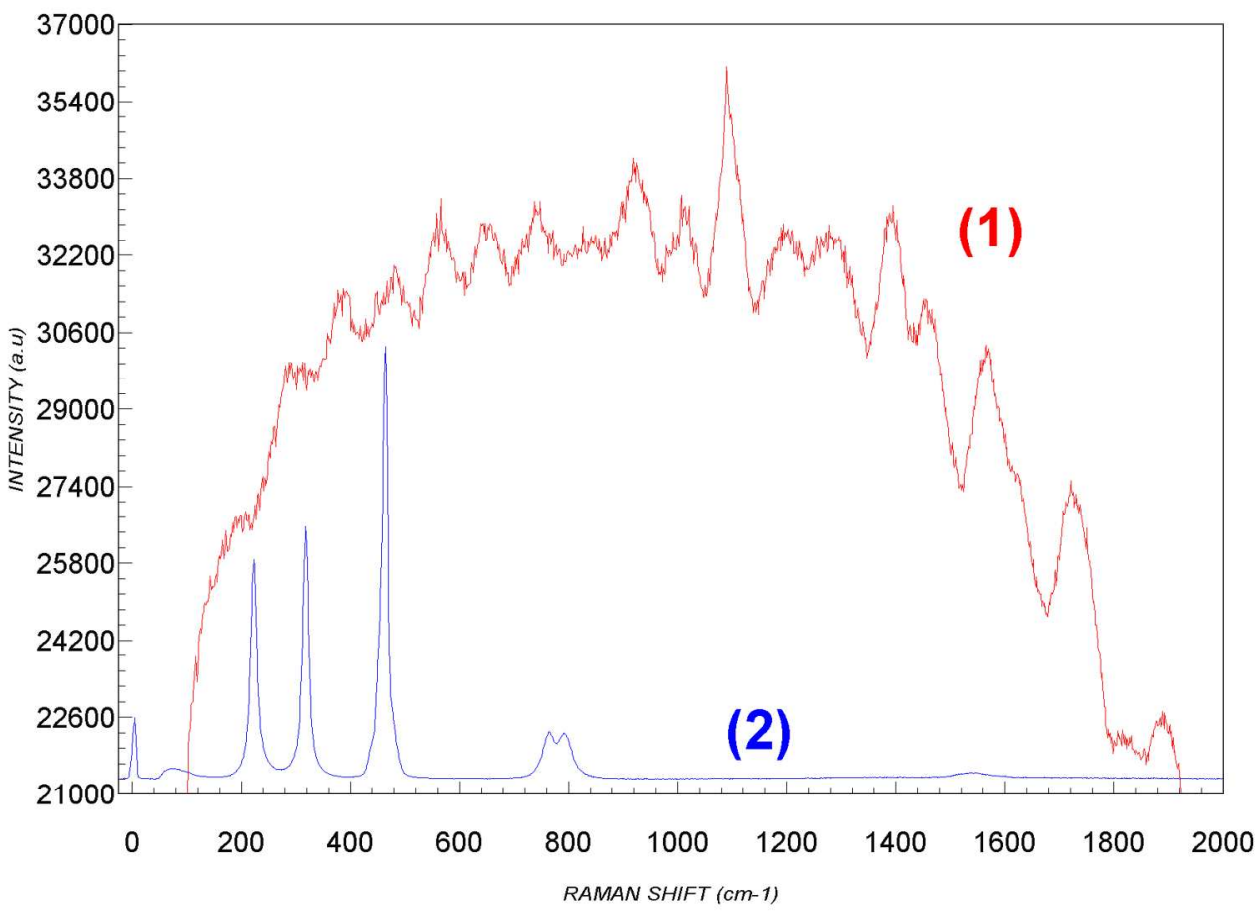

Raman spectra taken with the $785 \mathrm{~nm}$ device described in this article. (1) Limestone (polished solid). (2) Carbon tetrachloride (liquid). Both spectra uncorrected. 


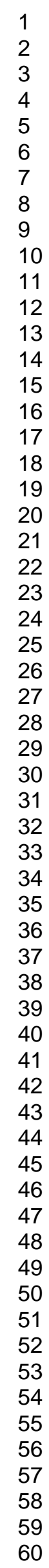

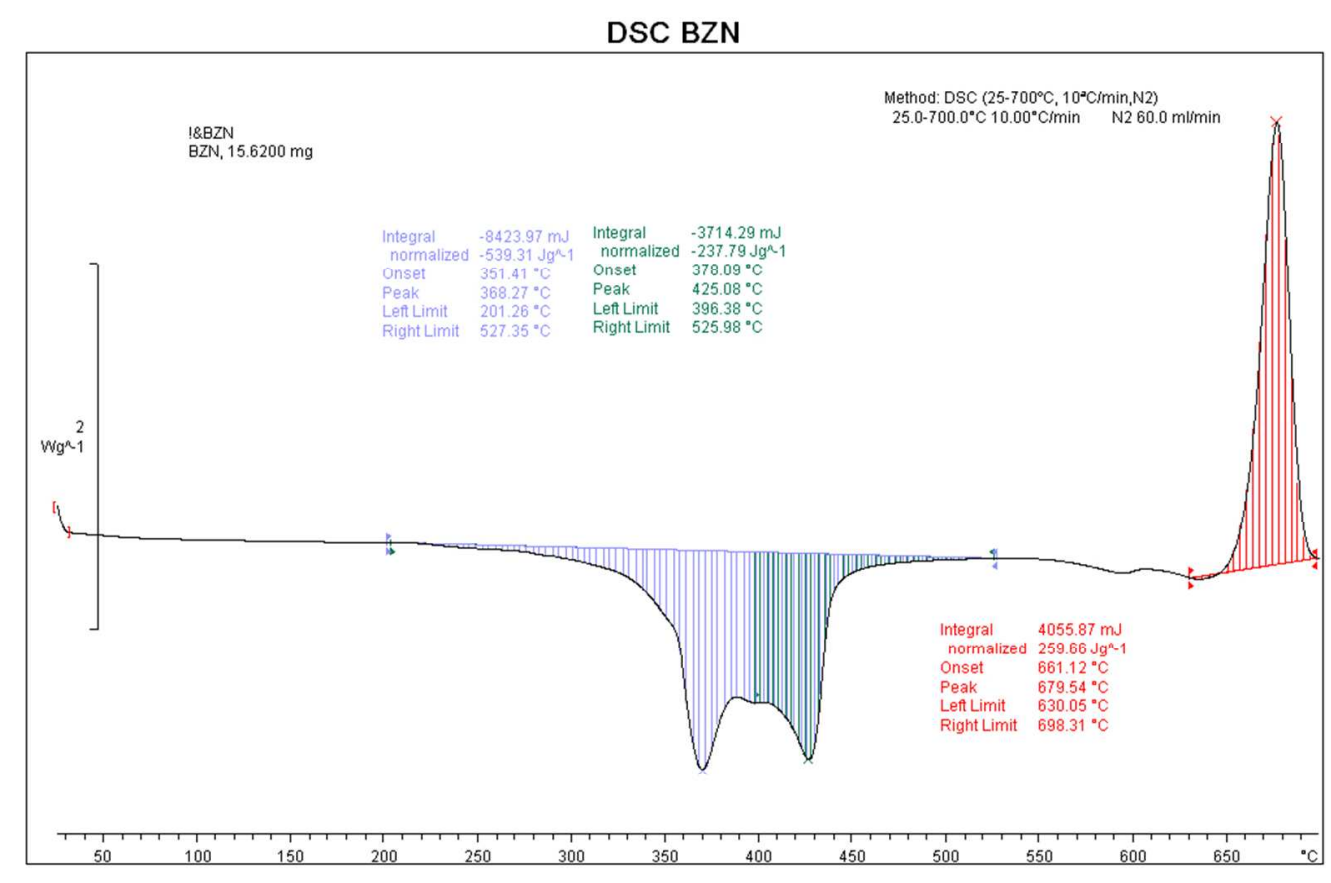

DSC analysis of a $\mathrm{Zn3B6O12.3,5H2O} \mathrm{sample.}$ 


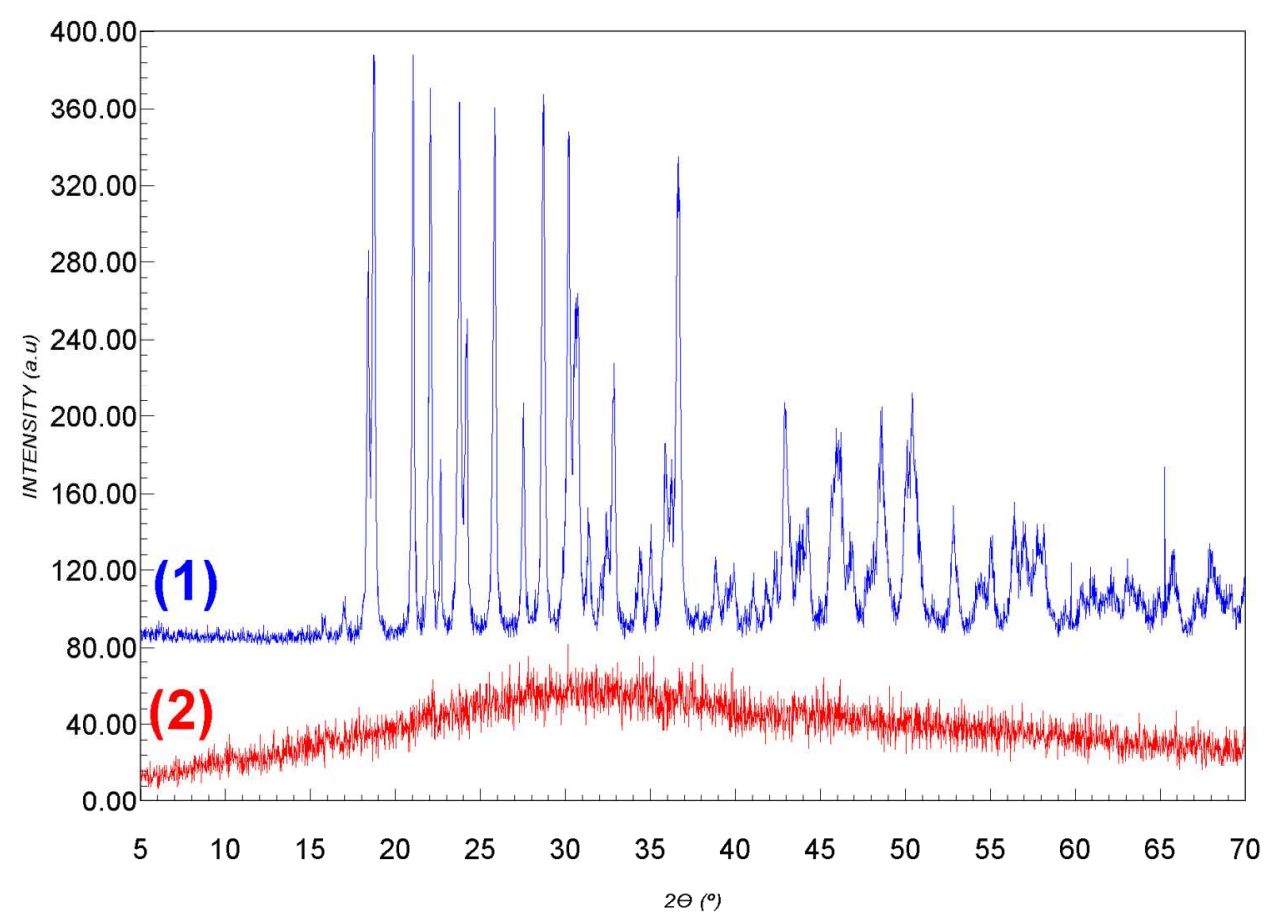

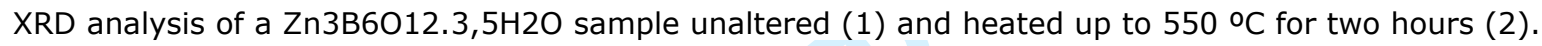


1

2

3

4

5

6

7

8

9

10

11

12

13

14

15

16

17

18

19

20

21

22

23

24

25

26

27

28

29

30

31

32

33

34

35

36

37

38

39

40

41

42

43

44

45

46

47

48

49

50

51

52

53

54

55

56

57

58

59

60

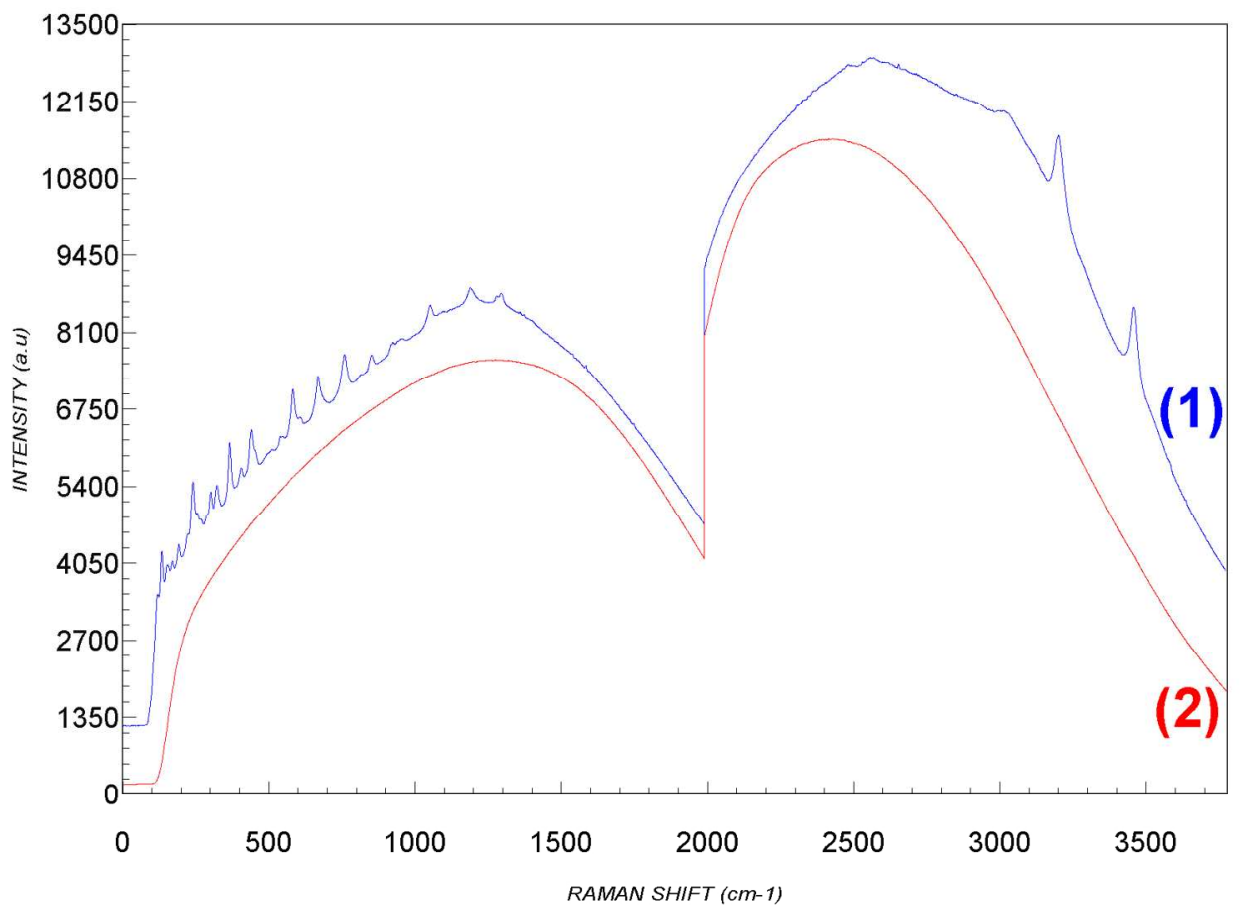

Raman analysis of a $\mathrm{Zn3B} 6 \mathrm{O} 12.3,5 \mathrm{H} 20$ sample unaltered (1) and heated up to $550^{\circ} \mathrm{C}$ for two hours (2). Both spectra uncorrected. 
Comparison of the luminescence spectrum of A-ZB as obtained with different instruments: (1) $532 \mathrm{~nm},(2)$ $633 \mathrm{~nm},(3) 785 \mathrm{~nm},(4) 1064 \mathrm{~nm}$. Spectra intensity normalized to unit. 
1

2

3

4

5

6

7

8

9

10

11

12

13

14

15

16

17

18

19

20

21

22

23

24

25

26

27

28

29

30

31

32

33

34

35

36

37

38

39

40

41

42

43

44

45

46

47

48

49

50

51

52

53

54

55

56

57

58

59

60

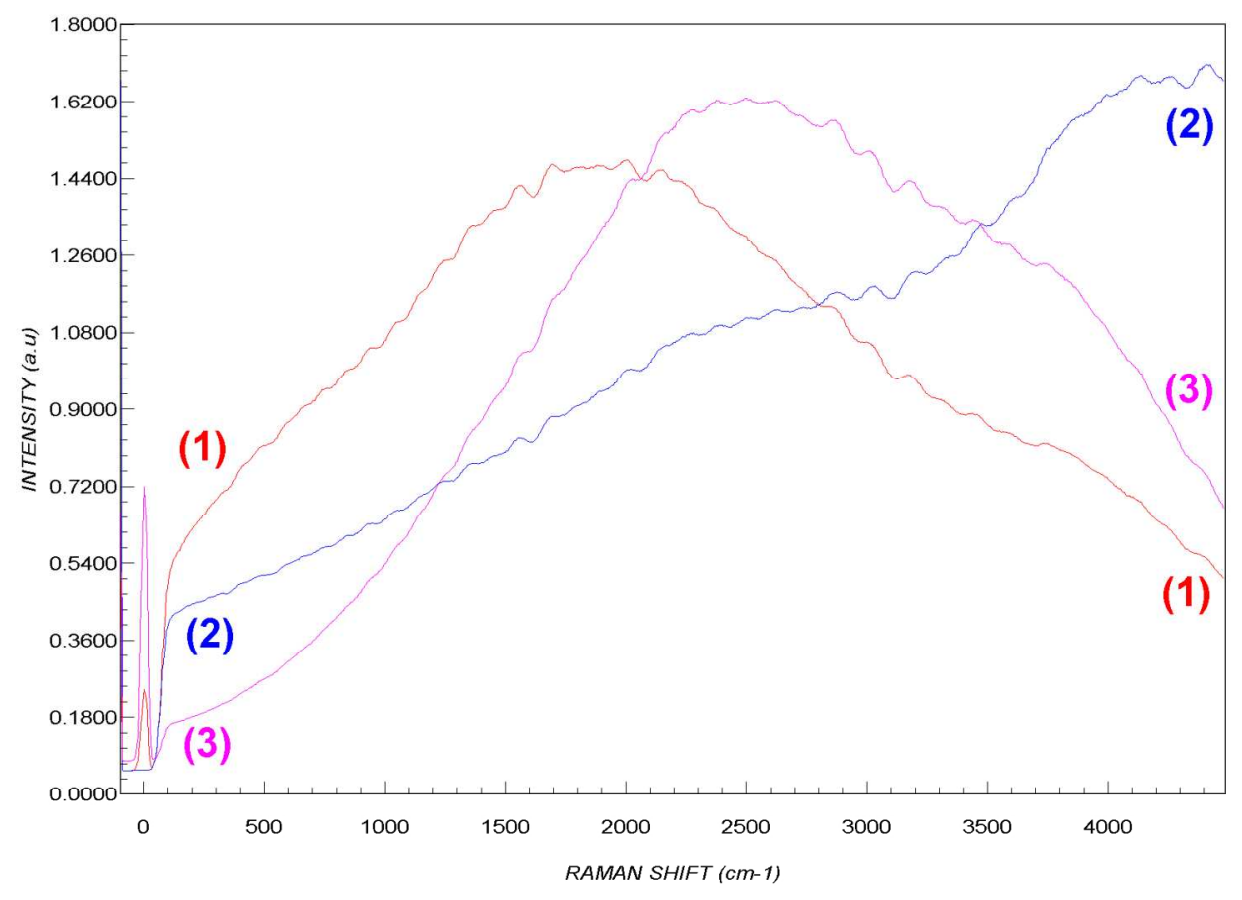

comparison between the spectrum of the A-ZB luminescence (1), the KOSI HCA calibration lamp emission (2), and the NIST SRM 2242 or 2241 (3). Spectra intensity normalized to unit. With the $532 \mathrm{~nm}$ spectrometer. 


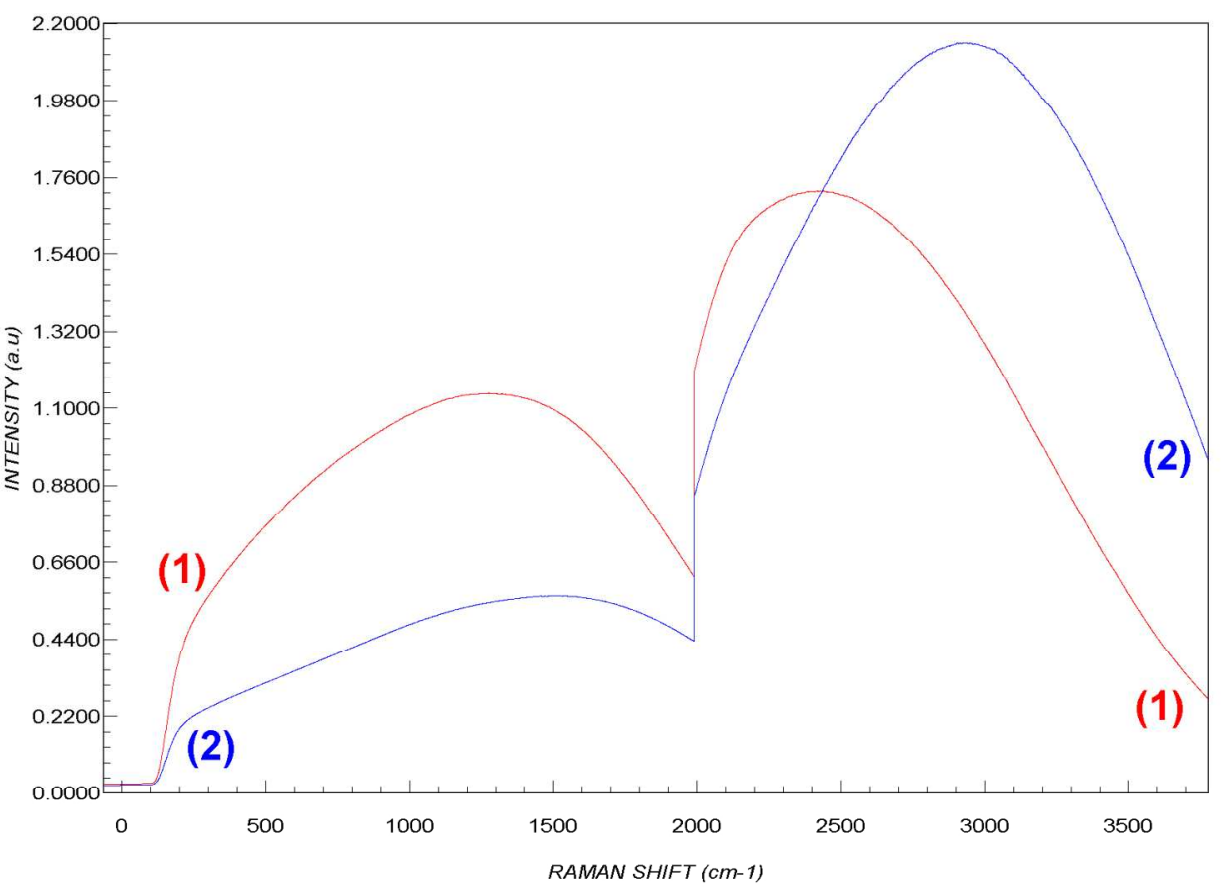

Same comparisson as figure $5 a$ for a $633 \mathrm{~nm}$ 


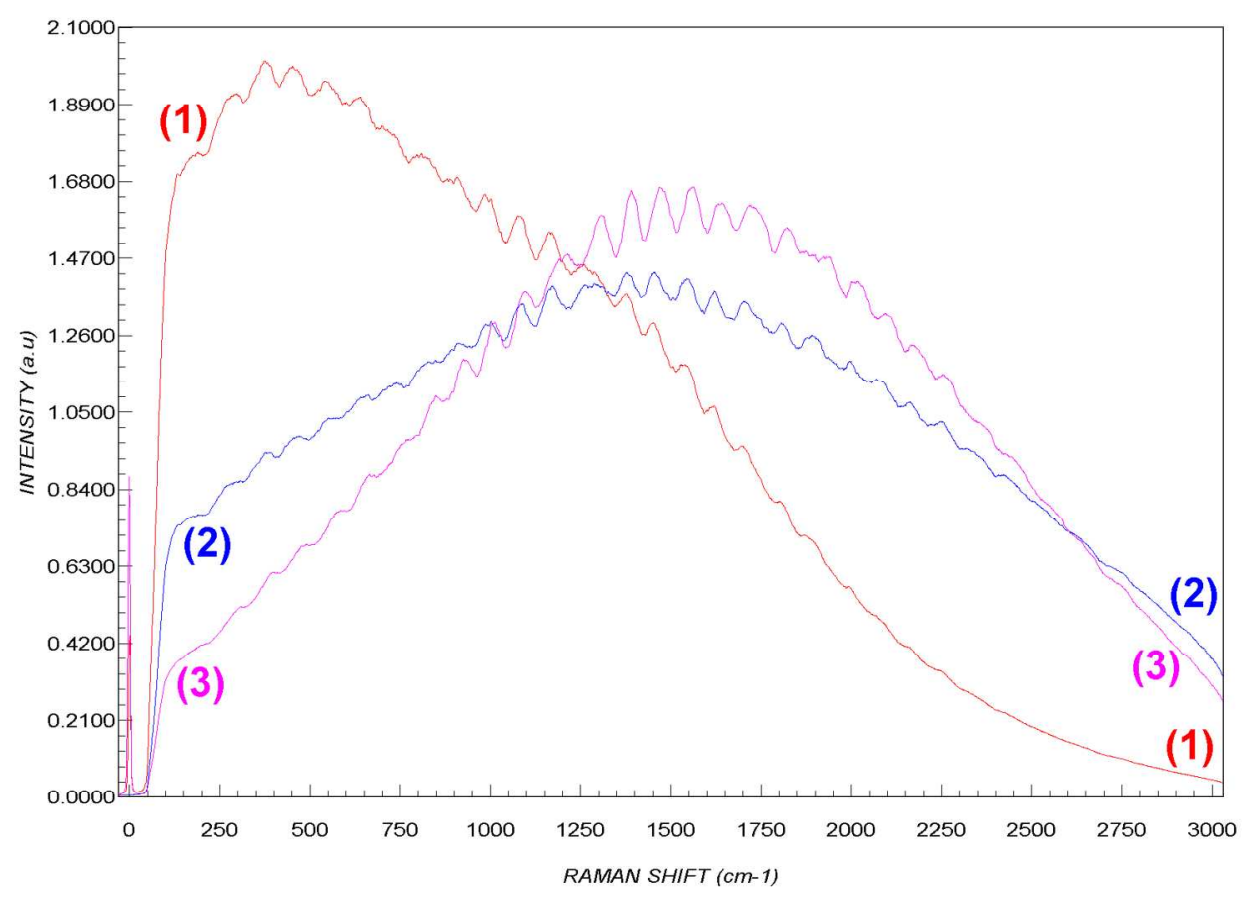

Same comparisson as figure 5 a for a $785 \mathrm{~nm}$ 


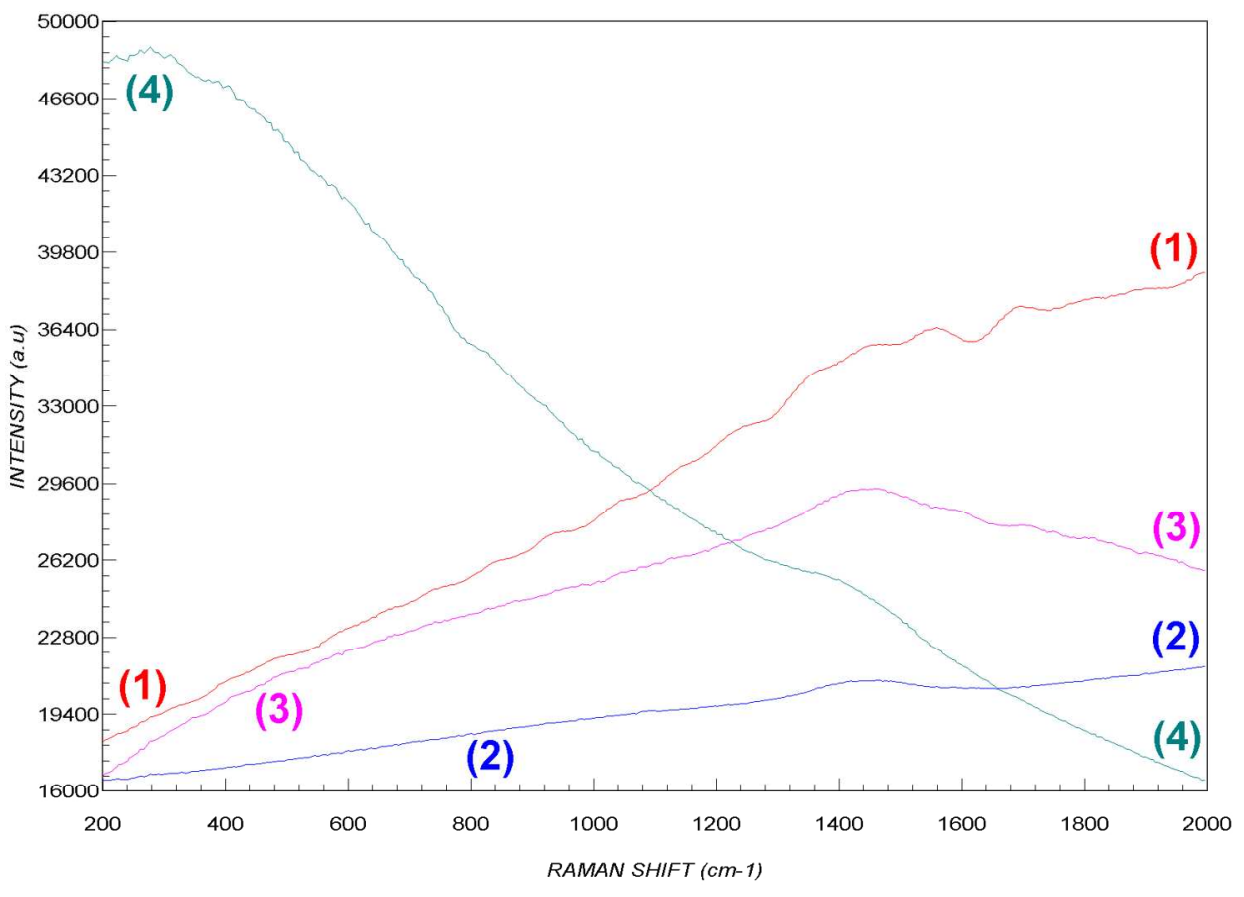

$532 \mathrm{~nm}$ Raman limestone spectra, (1) original, (2) A-ZB corrected, (3) KOSI HCA lamp corrected, (4) NIST SRM 2242 corrected. 


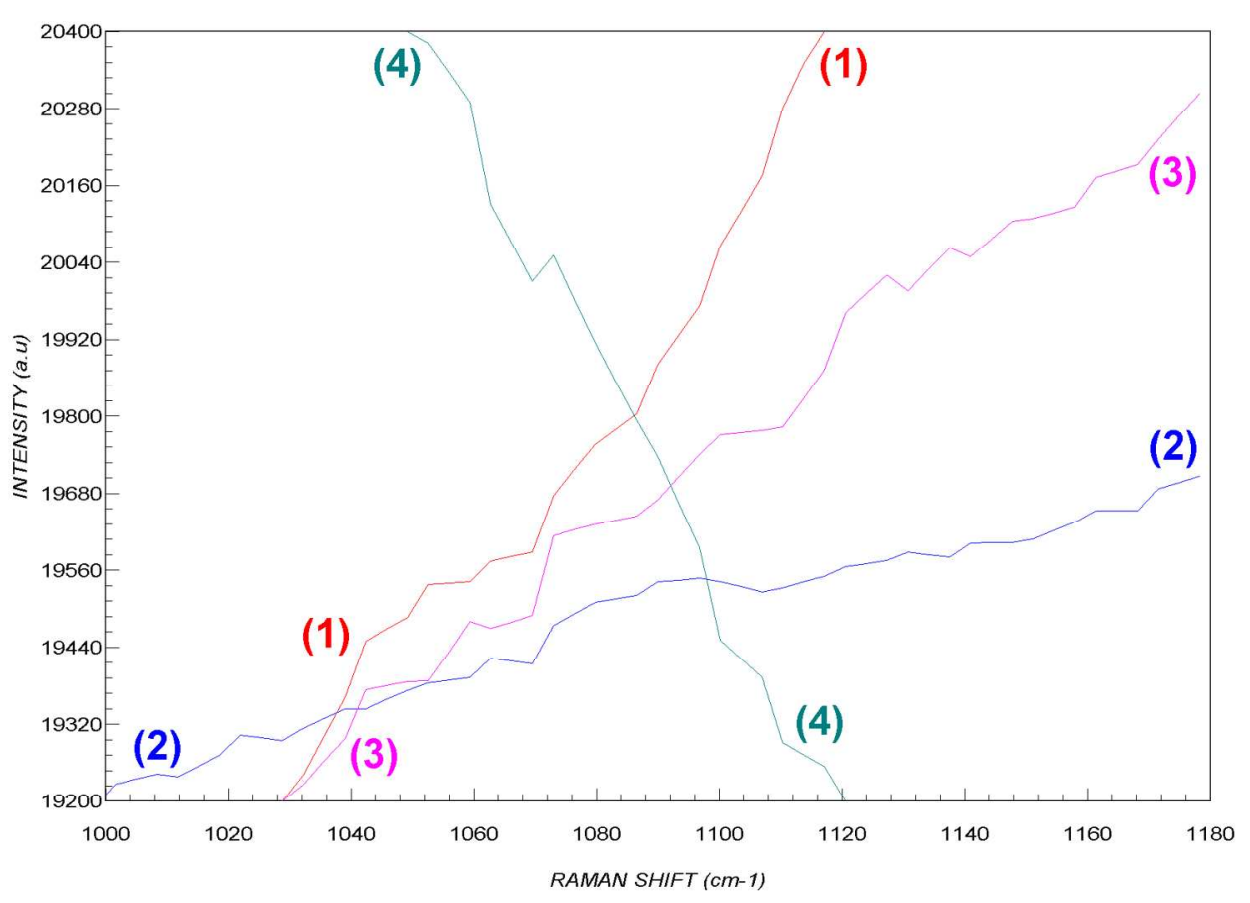

detail of limestone's main band region around $1086 \mathrm{~cm}-1$. 


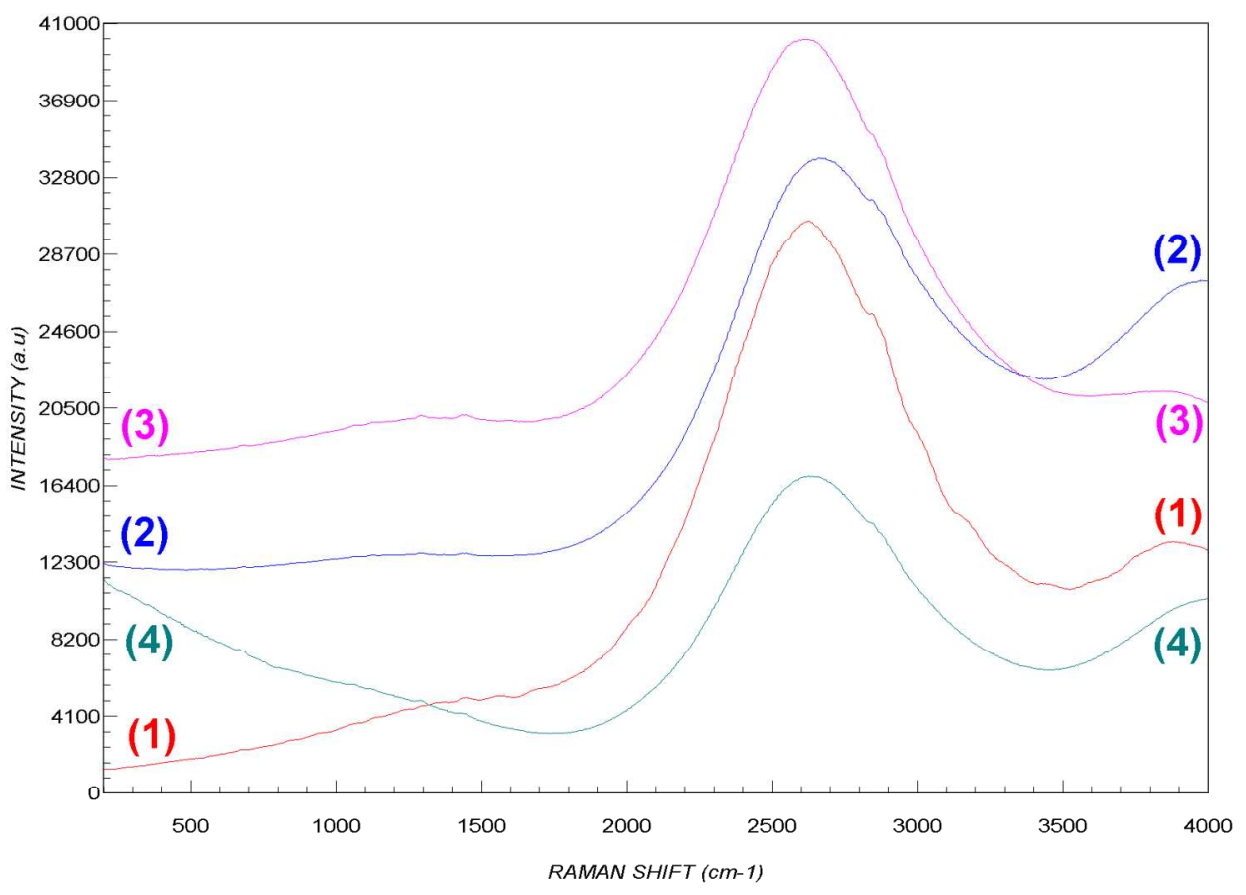

$532 \mathrm{~nm}$ Raman spectrum of PE+talc, (1) original, (2) A-ZB corrected, (3) KOSI HCA lamp corrected, (4) NIST SRM 2242 corrected. 
1

2

3

4

5

6

7

8

9

10

11

12

14

15

16

17

18

19

20

21

22

23

24

25

26

27

28

29

30

31

32

33

34

35

36

37

38

39

40

41

42

43

44

45

46

47

48

49

50

51

52

53

54

55

56

57

58

59

60

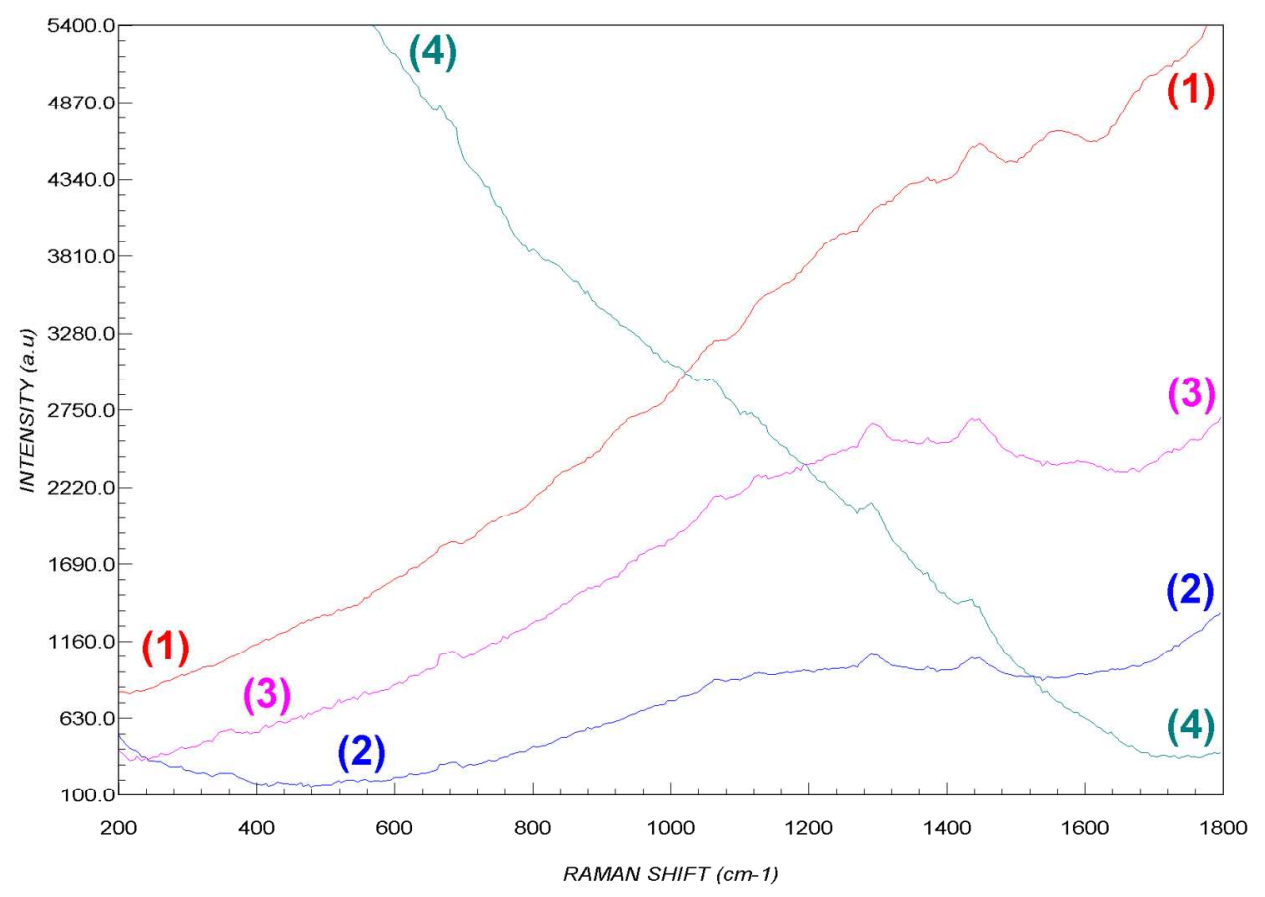

detail of the low Raman shift region 
Raman spectra using $532 \mathrm{~nm}$ of a limestone sample, (1) 1 scan, (2) 50 scan, keeping all the other acquisition parameters the same. 
1

2

3

4

5

6

7

8

9

10

11

12

13

14

15

16

17

18

19

20

21

22

23

24

25

26

27

28

29

30

31

32

33

34

35

36

37

38

39

40

41

42

43

44

45

46

47

48

49

50

51

52

53

54

55

56

57

58

59

60

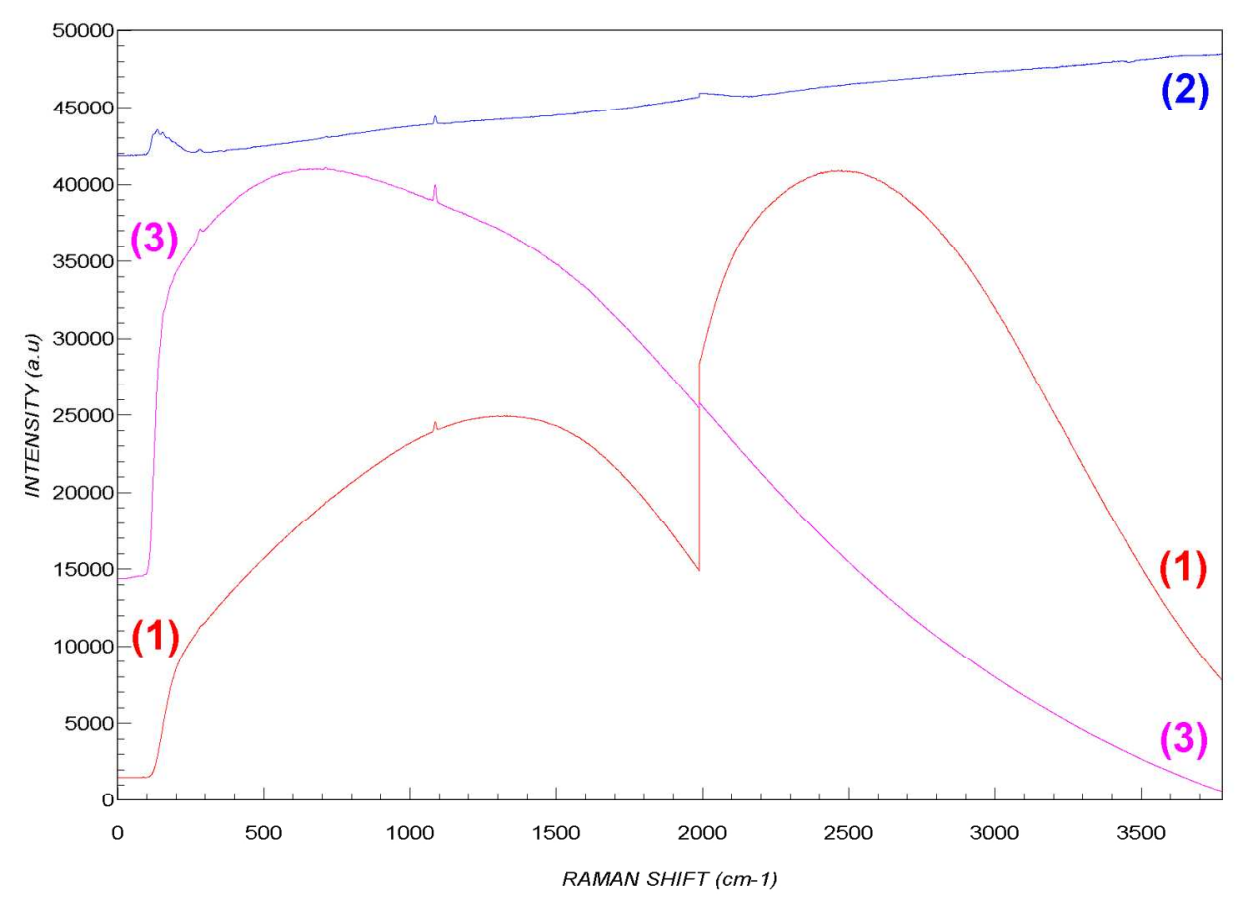

Figure 9a: $633 \mathrm{~nm}$ Raman spectra of a limestone sample (1) original, (2) A-ZB corrected, (3) KOSI HCA lamp corrected. 


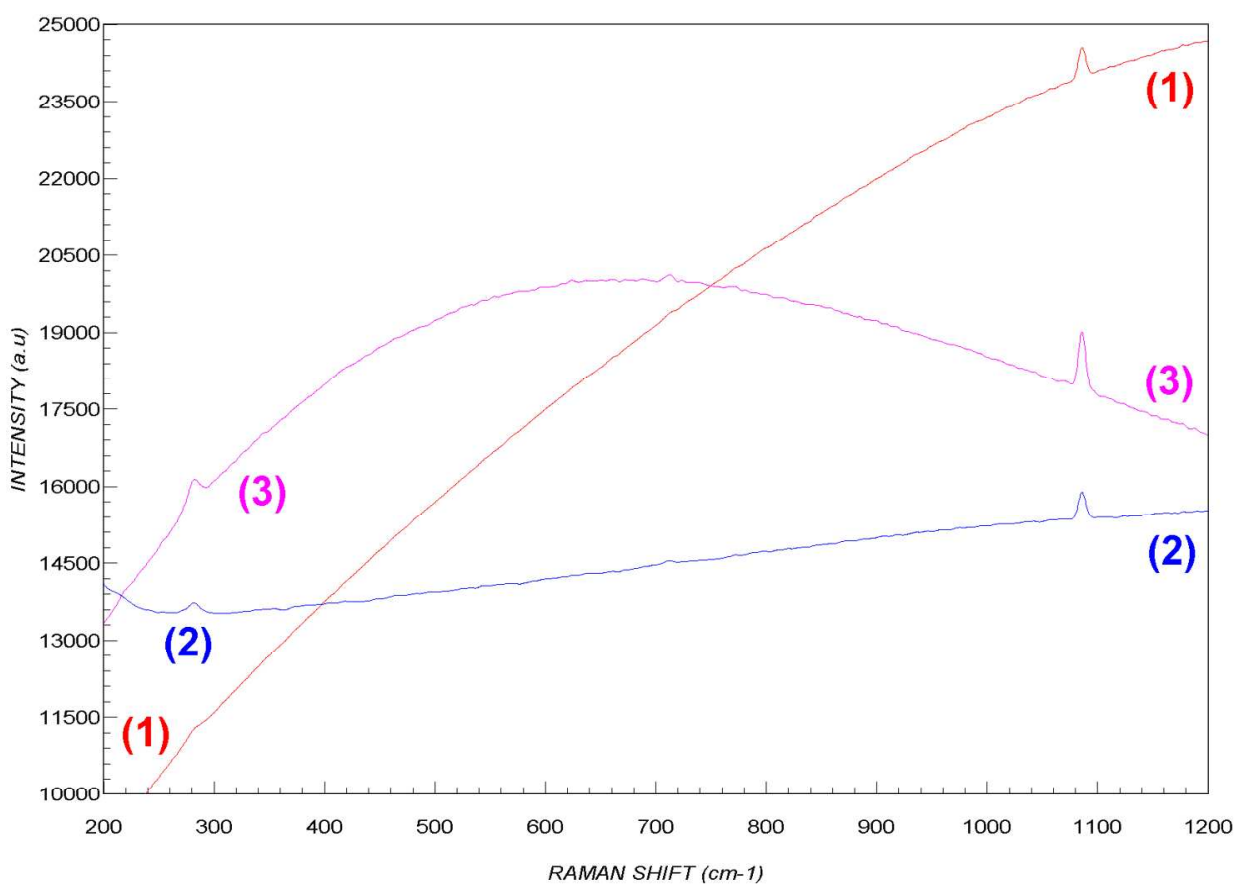

Detail of the Raman signals range from the previous figure. 
1

2

3

4

5

6

7

8

9

10

11

12

13

14

15

16

17

18

19

20

21

22

23

24

25

26

27

28

29

30

31

32

33

34

35

36

37

38

39

40

41

42

43

44

45

46

47

48

49

50

51

52

53

54

55

56

57

58

59

60

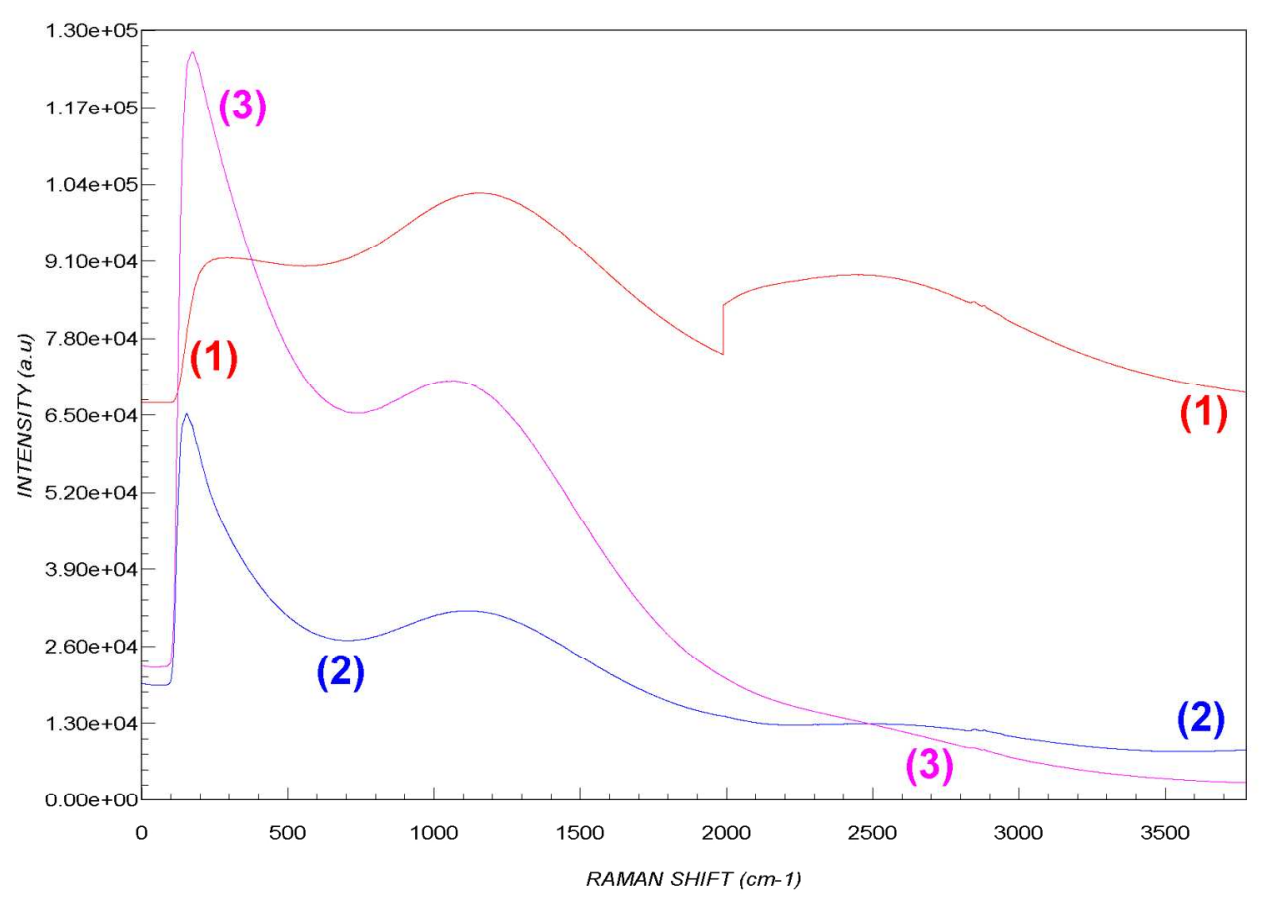

$633 \mathrm{~nm}$ Raman spectra of PE+talc, (1) original, (2) A-ZB corrected, (3) KOSI HCA lamp corrected. 


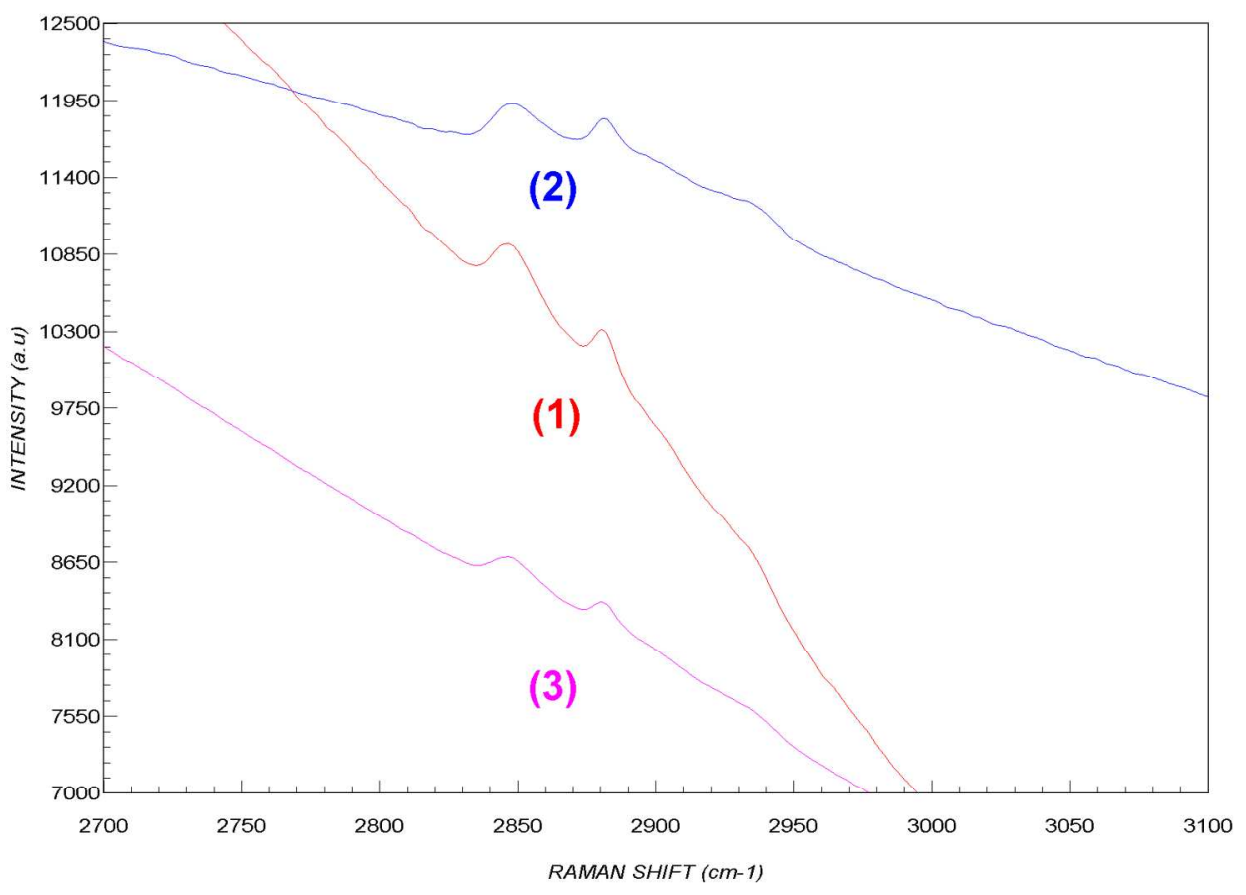

Detailed view of the Raman signals around $2900 \mathrm{~cm}-1$. 
1

2

3

4

5

6

7

8

9

10

11

12

13

14

15

16

17

18

19

20

21

22

23

24

25

26

27

28

29

30

31

32

33

34

35

36

37

38

39

40

41

42

43

44

45

46

47

48

49

50

51

52

53

54

55

56

57

58

59

60

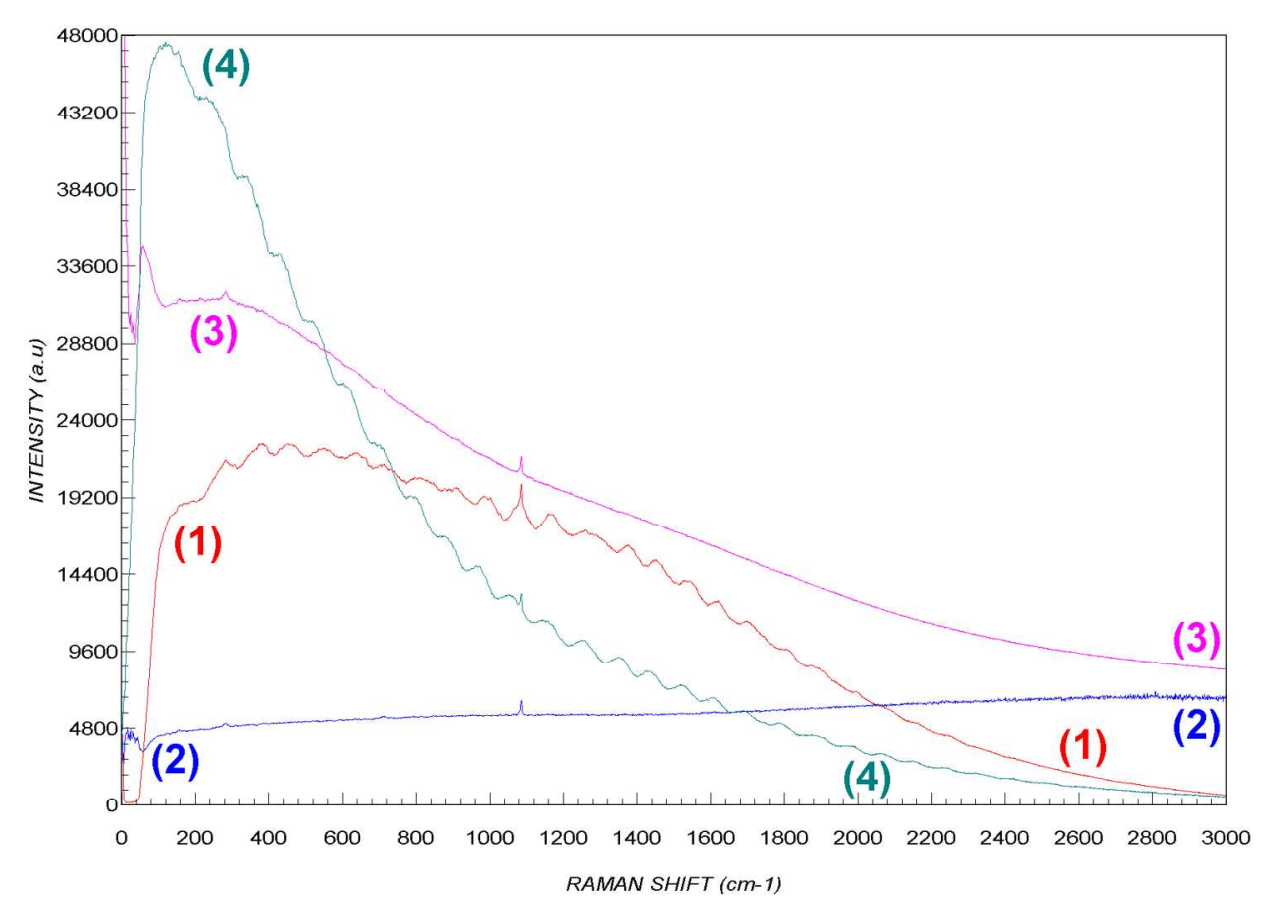

$785 \mathrm{~nm}$ spectra of a limestone sample, (1) original, (2) A-ZB corrected, (3) KOSI HCA lamp corrected, (4) NIST SRM 2241 corrected. 


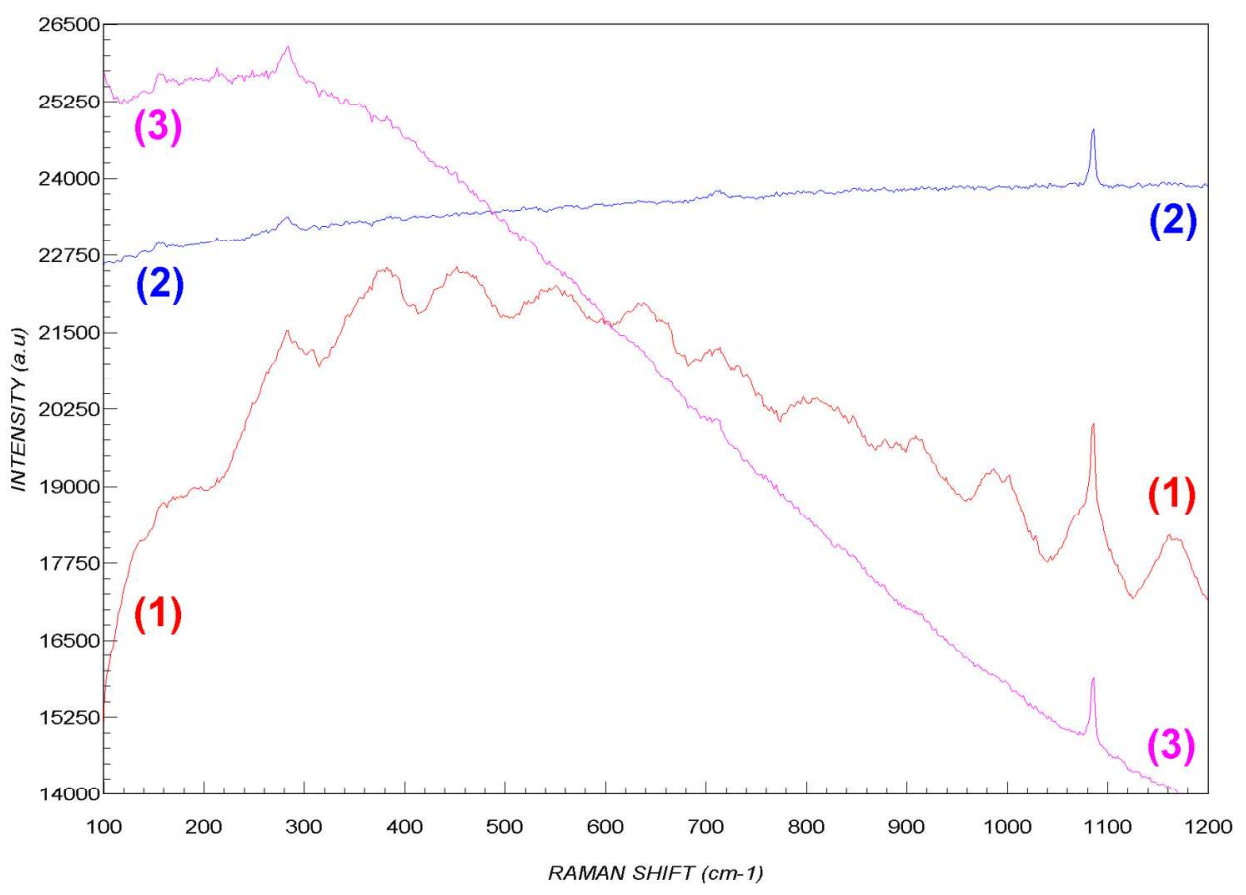

Detail of the region of interest (without the SRM 2241 spectrum). 


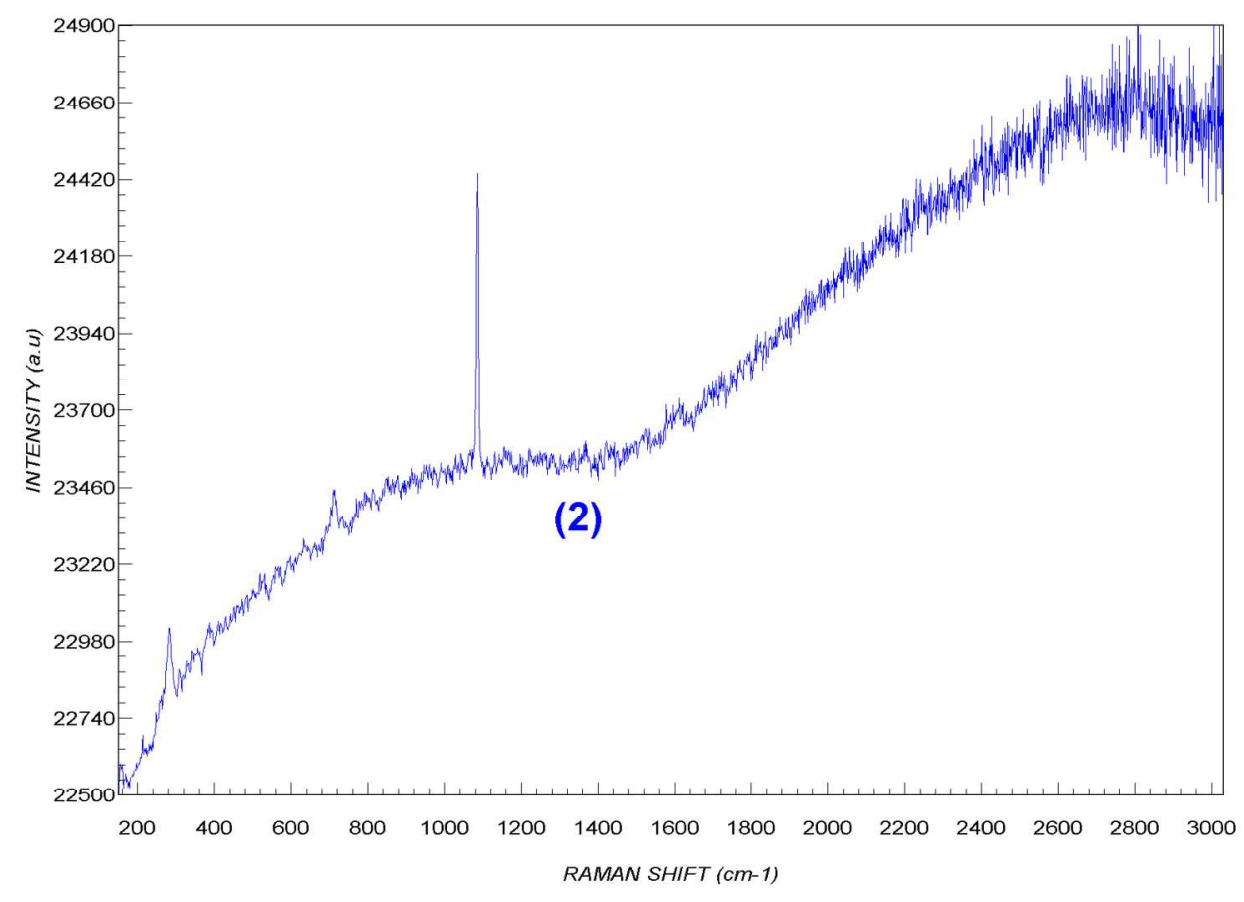

Detail of spectrum (2), showing how well A-ZB corrects the etaloning artifacts. 


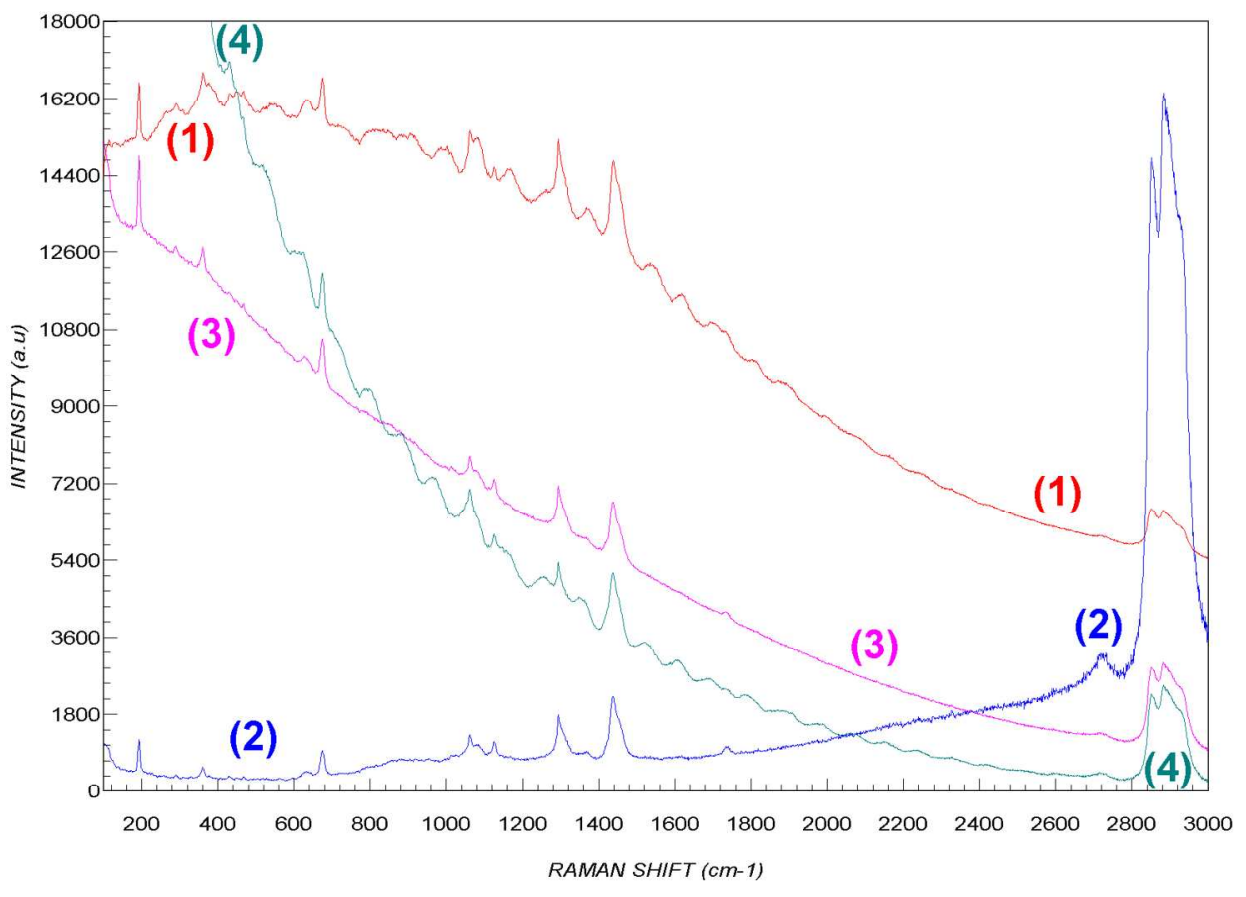

$785 \mathrm{~nm}$ Raman spectra of PE+talc, (1) original, (2) A-ZB corrected, (3) KOSI HCA lamp corrected, (4) NIST SRM 2241 corrected. 


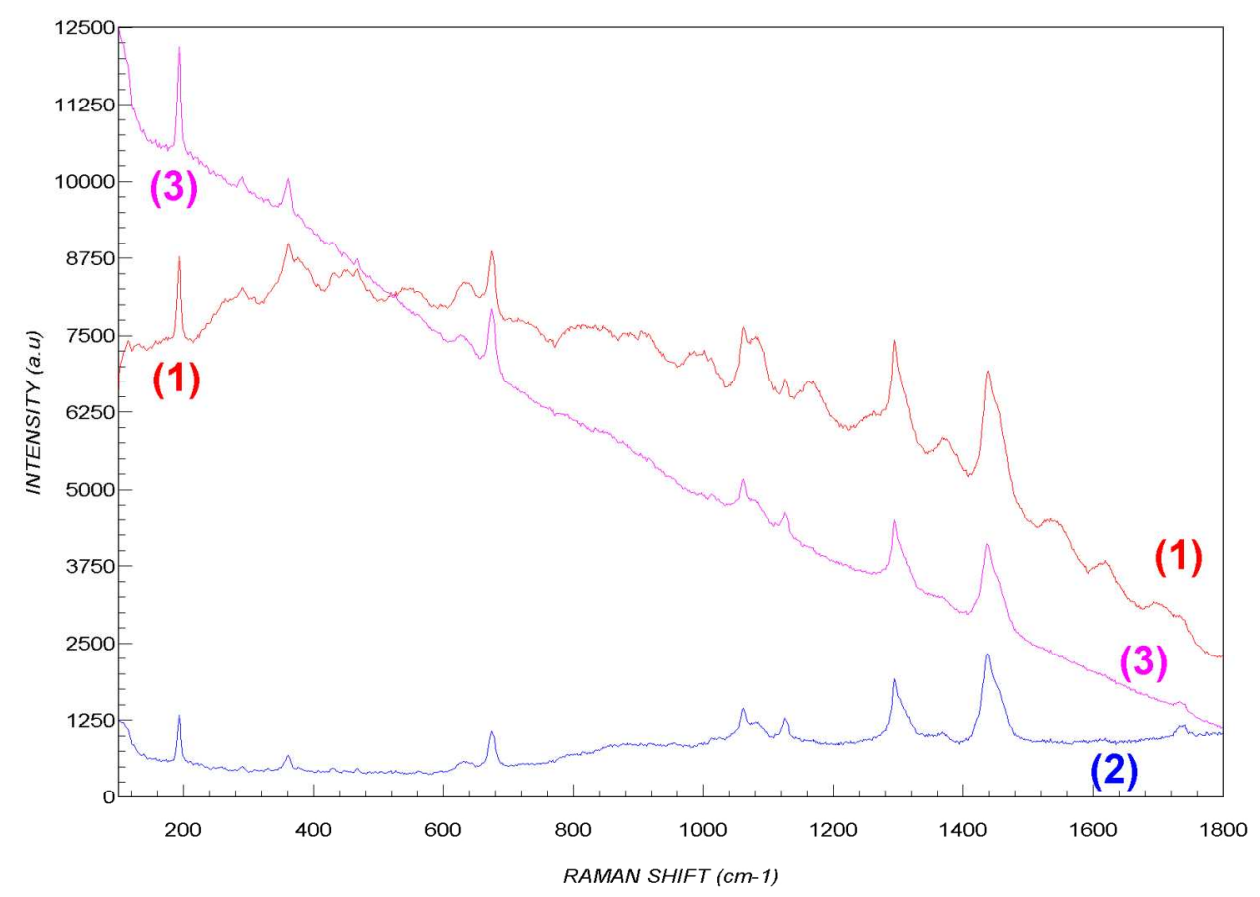

Detail of the low Raman shift region (without the SRM 2241 spectrum). 


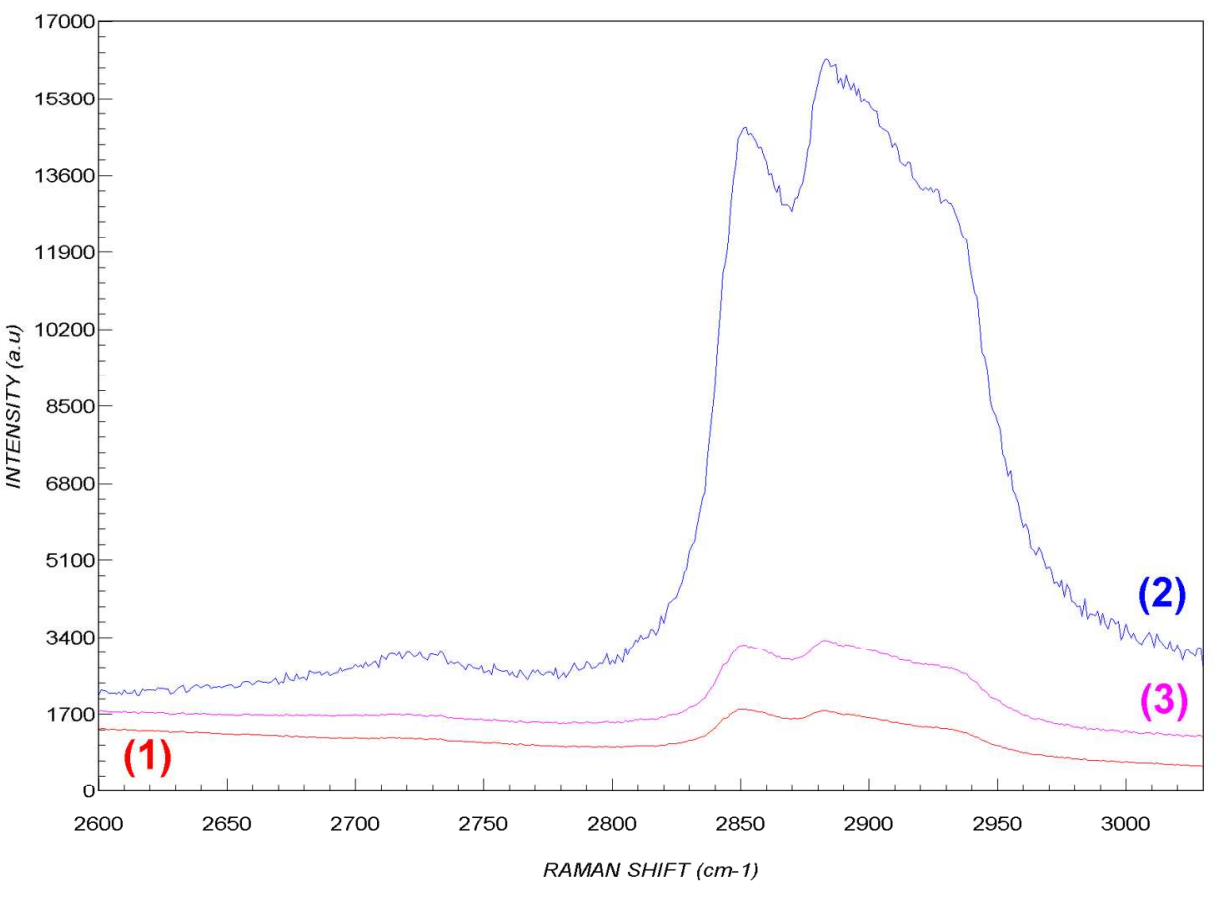

Detail of the range around $2900 \mathrm{~cm}-1$. 


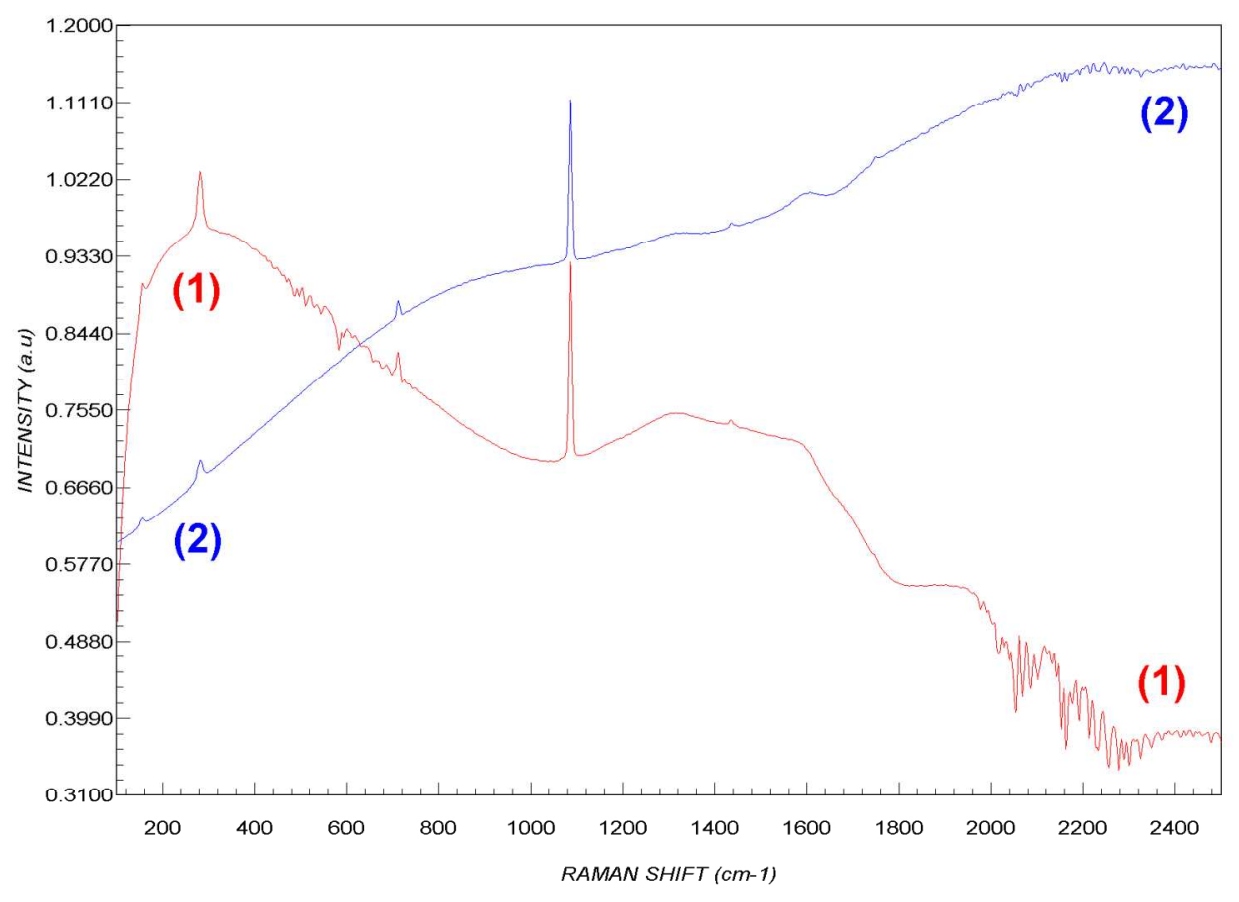

FT-Raman spectra of a limestone, sample (1) original, (2) A-ZB corrected. 


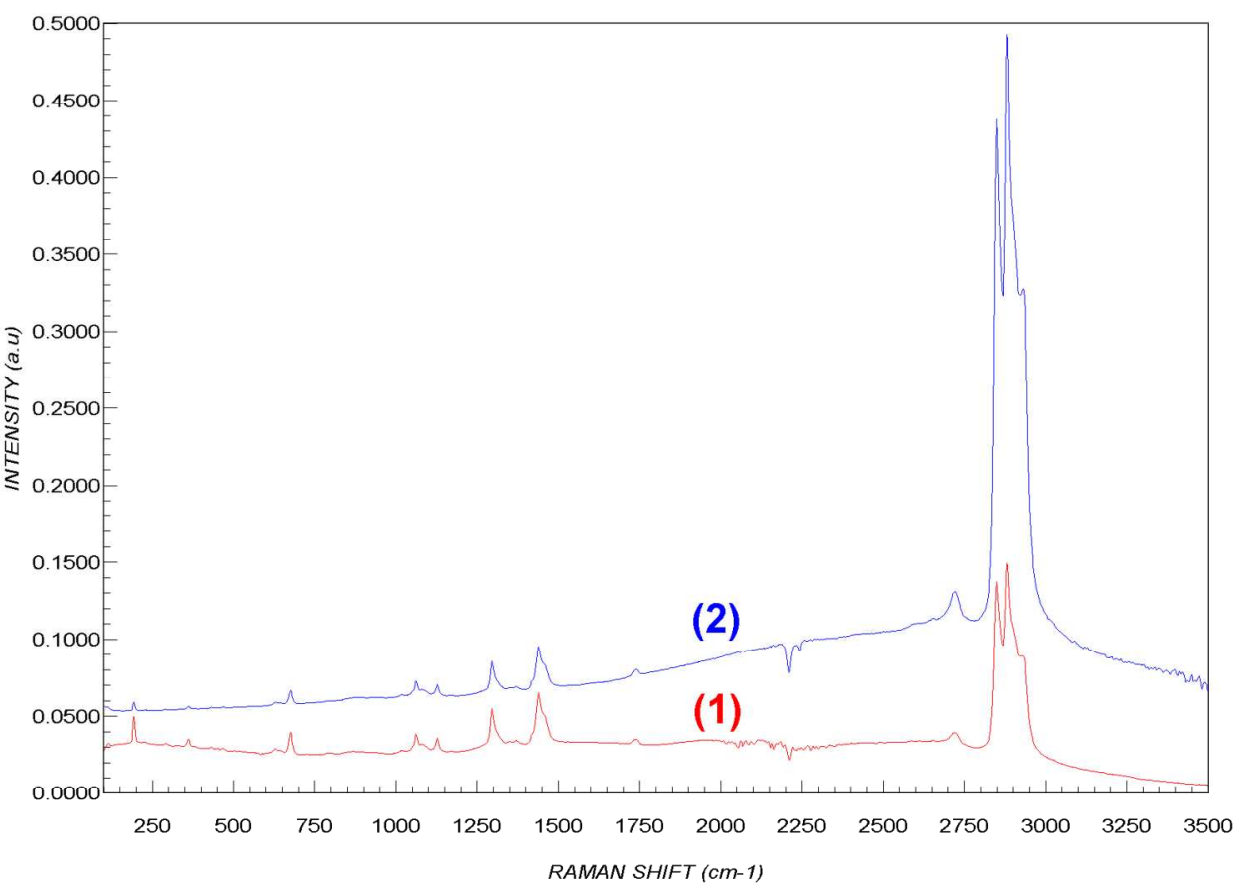

FT-Raman spectra of PE+talc, (1) original, (2) A-ZB corrected. 
1

2

3

4

5

6

7

8

9

10

11

12

13

14

15

16

17

18

19

20

21

22

23

24

25

26

27

28

29

30

31

32

33

34

35

36

37

38

39

40

41

42

43

44

45

46

47

48

49

50

51

52

53

54

55

56

57

58

59

60

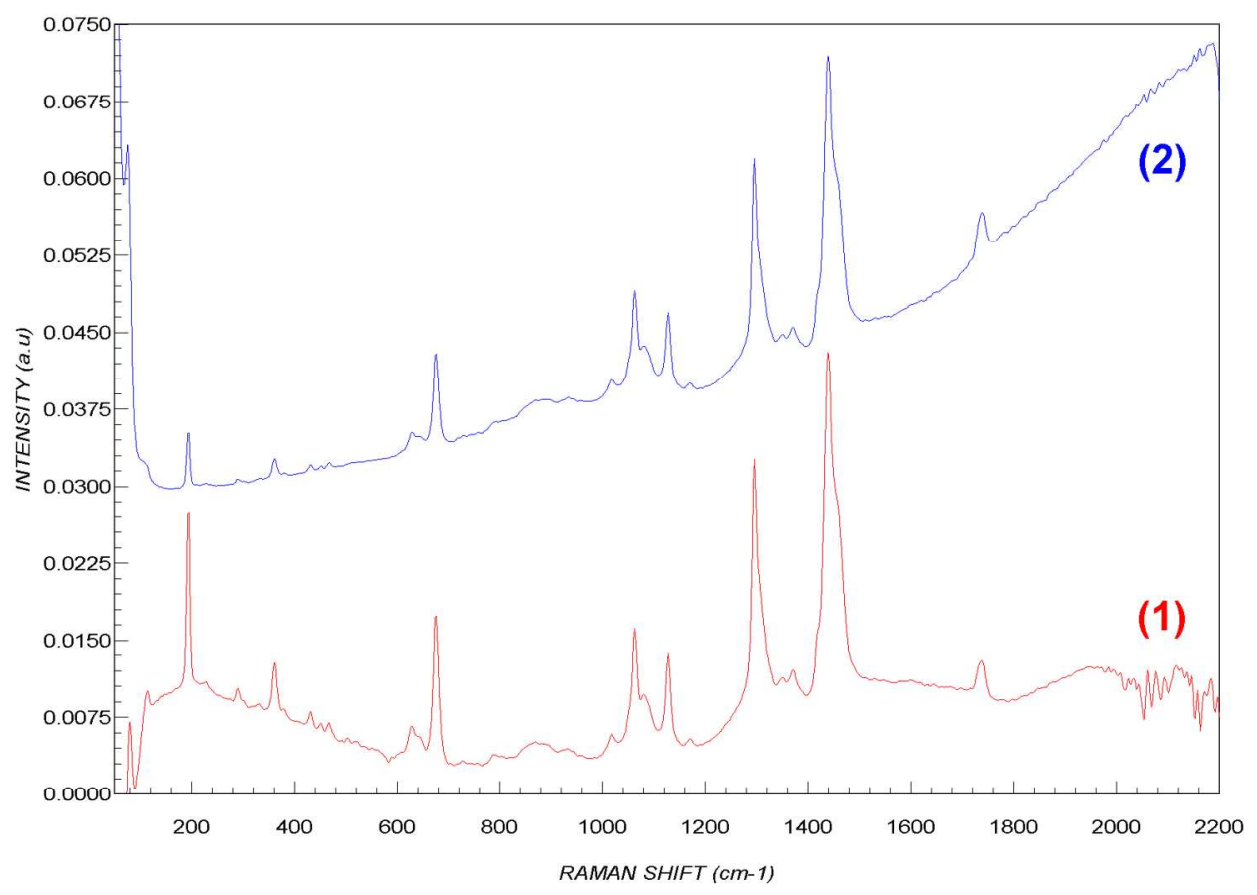

Detail of the low Raman shift region. 


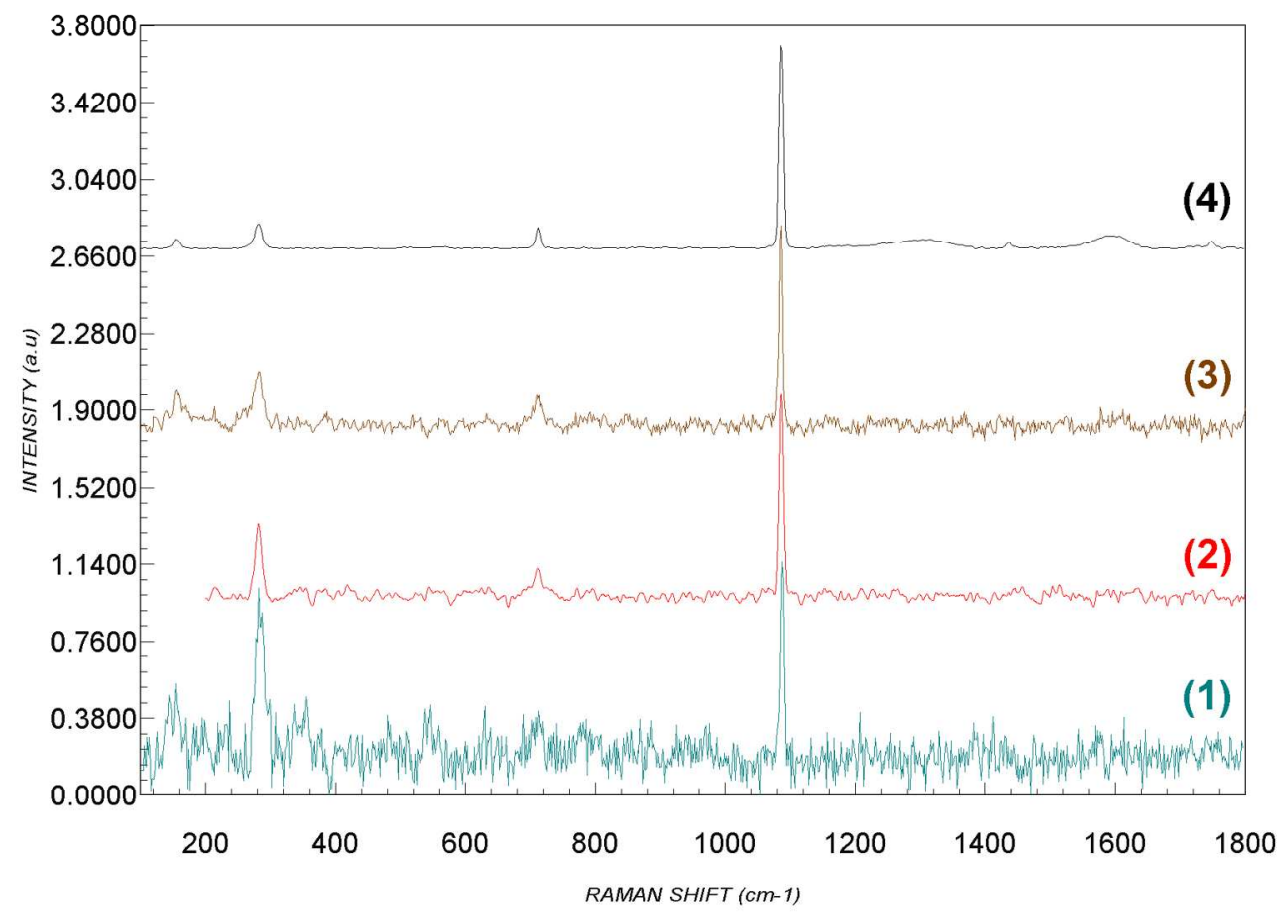

Spectra A-ZB corrected. (1) 532 nm, (2) 633 nm, (3) 785 mn, (4) FT-Raman 1064 nm. Limestone sample. 


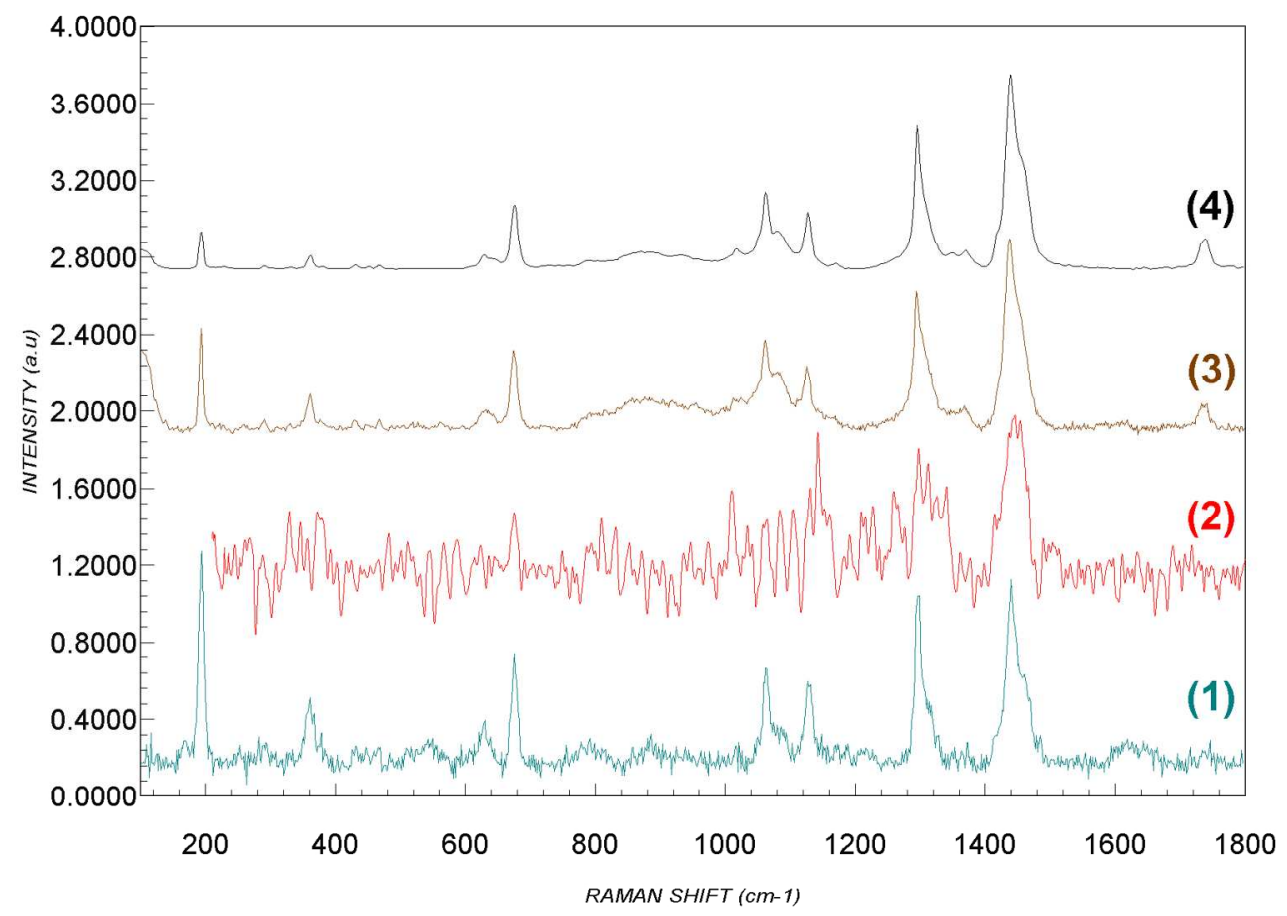

Same comparisson as figure 15 a for PE+talc sample (low Raman shift). 


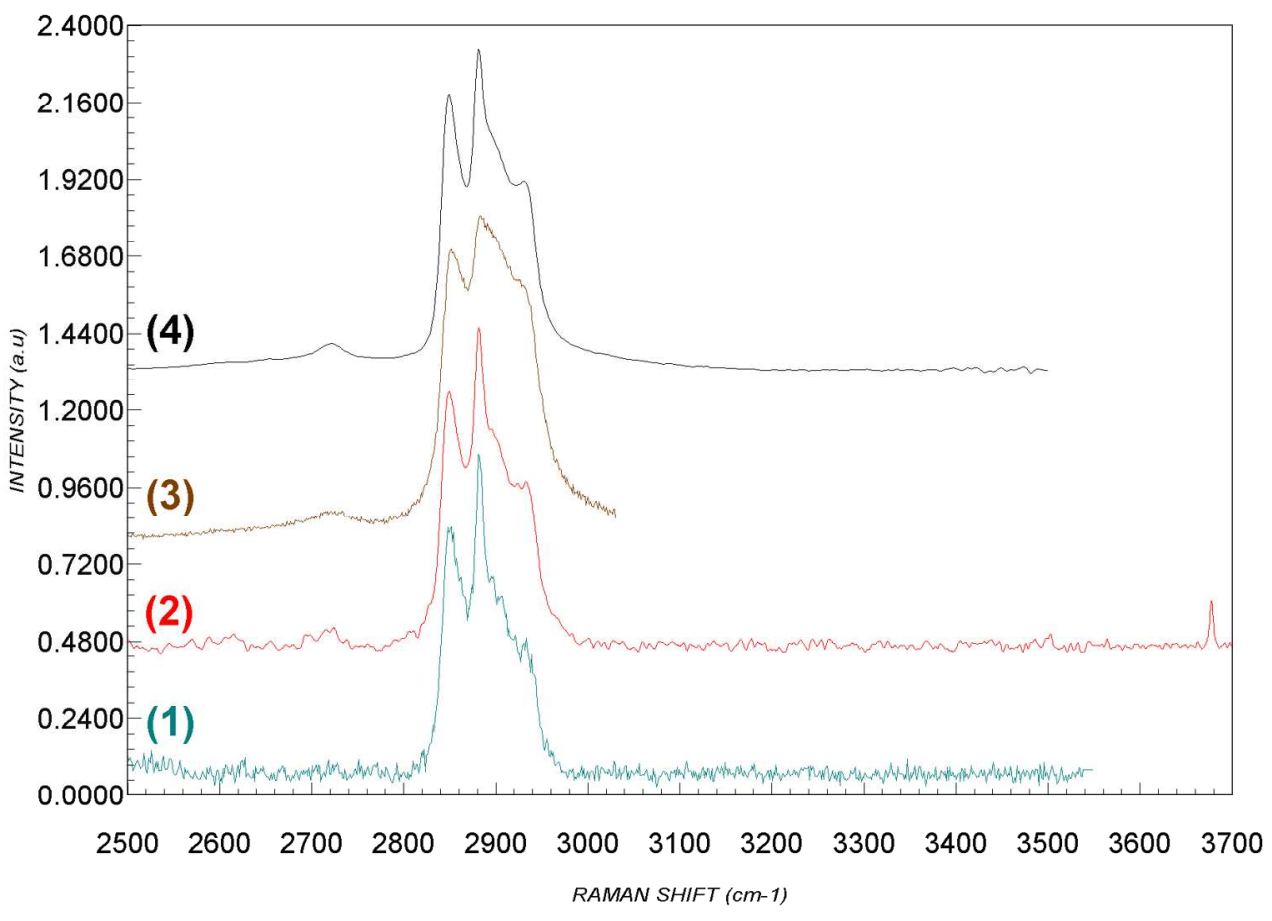

Same comparisson as figure 15 a for PE+talc sample (high Raman shift). 